\title{
SOA formation from the atmospheric oxidation of 2-methyl-3-buten-2-ol and its implications for $\mathbf{P M}_{2.5}$
}

\author{
M. Jaoui ${ }^{1}$, T. E. Kleindienst ${ }^{2}$, J. H. Offenberg ${ }^{2}$, M. Lewandowski ${ }^{2}$, and W. A. Lonneman ${ }^{3}$ \\ ${ }^{1}$ Alion Science and Technology, P.O. Box 12313, Research Triangle Park, NC 27709, USA \\ ${ }^{2}$ US Environmental Protection Agency, Office of Research and Development, National Exposure Research Laboratory, \\ Research Triangle Park, NC 27711, USA \\ ${ }^{3}$ EPA Senior Environmental Employee Program, US Environmental Protection Agency, Office of Research and Development, \\ National Exposure Research Laboratory, Research Triangle Park, NC 27711, USA \\ Correspondence to: M. Jaoui (jaoui.mohammed@epa.gov)
}

Received: 30 June 2011 - Published in Atmos. Chem. Phys. Discuss.: 26 August 2011

Revised: 30 January 2012 - Accepted: 11 February 2012 - Published: 27 February 2012

\begin{abstract}
The formation of secondary organic aerosol (SOA) generated by irradiating 2-methyl-3-buten-2-ol (MBO) in the presence and/or absence of $\mathrm{NO}_{\mathrm{x}}, \mathrm{H}_{2} \mathrm{O}_{2}$, and/or $\mathrm{SO}_{2}$ was examined. Experiments were conducted in smog chambers operated in either dynamic or static mode. A filter/denuder sampling system was used for simultaneously collecting gas- and particlephase products. The structural characterization of gas and particulate products was investigated using BSTFA, BSTFA + PFBHA, and DNPH derivatization techniques followed by GC-MS and liquid chromatography analysis. This analysis showed the occurrence of more than 68 oxygenated organic compounds in the gas and particle phases, 28 of which were tentatively identified. The major components observed include 2,3-dihydroxyisopentanol (DHIP), 2-hydroxy-2-oxoisopentanol, 2,3-dihydroxy-
\end{abstract} 3-methylbutanal, 2,3-dihydroxy-2-methylsuccinic acid, 2-hydroxy-2-methylpropanedioic acid, acetone, glyoxal, methylglyoxal, glycolaldehyde, and formaldehyde. Most of these oxygenated compounds were detected for the first time in this study.

While measurements of the gas-phase photooxidation products have been made, the focus of this work has been an examination of the particle phase. SOA from some experiments was analyzed for the organic mass to organic carbon ratio $(\mathrm{OM} / \mathrm{OC})$, the effective enthalpy of vaporization $\left(\Delta \mathrm{H}_{\mathrm{vap}}^{\text {eff }}\right)$, and the aerosol yield. Additionally, aerosol size, volume, and number concentrations were measured by a Scanning Mobility Particle Sizer coupled to a Condensation Particle Counter system. The OM/OC ratio was 2.1 in the $\mathrm{MBO} / \mathrm{H}_{2} \mathrm{O}_{2}$ system. The $\Delta \mathrm{H}_{\text {vap }}^{\text {eff }}$ was $41 \mathrm{~kJ} \mathrm{~mol}^{-1}$, a value similar to that of isoprene SOA. The laboratory SOA yield measured in this study was $0.7 \%$ in $\mathrm{MBO} / \mathrm{H}_{2} \mathrm{O}_{2}$ for an aerosol mass of $33 \mu \mathrm{g} \mathrm{m}^{-3}$. Secondary organic aerosol was found to be negligible under conditions with oxides of nitrogen $\left(\mathrm{NO}_{\mathrm{x}}\right)$ present. Time profiles and proposed reaction schemes are provided for selected compounds.

The contribution of SOA products from MBO oxidation to ambient $\mathrm{PM}_{2.5}$ was investigated by analyzing a series of ambient $\mathrm{PM}_{2.5}$ samples collected in several places around the United States. In addition to the occurrence of several organic compounds in both field and laboratory samples, DHIP was found to originate only from the oxidation of $\mathrm{MBO}$, and therefore this compound could potentially serve as a tracer for MBO SOA. Initial attempts have been made to quantify the concentrations of DHIP and other compounds based on surrogate compound calibrations. The average concentrations of DHIP in ambient $\mathrm{PM}_{2.5}$ samples from Duke Forest in North Carolina ranged from zero during cold seasons to approximately $1 \mathrm{ng} \mathrm{m}^{-3}$ during warm seasons. This appears to be the first time that DHIP has been detected in ambient $\mathrm{PM}_{2.5}$ samples. The occurrence of several other compounds in both laboratory and field samples suggests that SOA originating from $\mathrm{MBO}$ can contribute under selected ambient conditions to the ambient aerosol mainly in areas where MBO emissions are high.

\section{Introduction}

Organic compounds of biogenic origin (BOCs) including isoprene, monoterpenes, sesquiterpenes, and oxygenated hydrocarbons are considered a significant class of organic species emitted from vegetation into the troposphere (Guenther et al., 1995). Since Went (1960) reported that oxidation of volatile organic compounds (VOCs) emitted by plants 
could lead to the formation of organic aerosol, considerable efforts have been devoted to understanding secondary organic aerosol (SOA) formation from ozonolysis reactions and ground-level ozone formation from BOCs (Kanakidou et al., 2005). SOA often constitutes a significant fraction of $\mathrm{PM}_{2.5}$ and can have significant impact on the physical and chemical characteristics of ambient aerosol affecting air quality from global to regional and local scales. A number of studies have shown the roles of $\mathrm{PM}_{2.5}$ in several atmospheric processes including visibility degradation (Sisler and Malm, 1994) and changes in radiative forcing that may affect the global climate (Charlson et al., 1992). Exposure to $\mathrm{PM}_{2.5}$ has been implicated in increases in human mortality and morbidity levels, and decreased PM levels have been shown to be associated with increased life expectancy (Pope et al., 2009). As the understanding of the toxicology associated with these particles develops, more accurate compositional data may be required.

Oxygenated biogenic compounds are generally not considered significant contributors to SOA formation due to their low reactivity and relatively low emission rates compared to isoprene and monoterpenes (Guenther et al., 1995, 2006; König et al., 1995). One exception appears to be the compound 2-methyl-3-butene-2-ol (MBO), which has been detected at high levels in ambient air and has been found to be produced and emitted in large quantities by many species of pine and fir trees (Goldan et al., 1993; Harley et al., 1998; Baker et al., 1999; Lamanna and Goldstein, 1999; Gray, 2008). Like isoprene, emissions of MBO have been found to be sensitive to light, temperature, and ecological factors (Harley et al., 1998; Gray, 2008). Moreover, the $\mathrm{MBO}+\mathrm{OH}$ reaction rate constant is similar to that of monoterpenes at $5.6 \times 10^{-11} \mathrm{~cm}^{3}$ molecule ${ }^{-1} \mathrm{~s}^{-1}$ (Carrasco et al., 2007) and leads to a MBO lifetime of approximately $2.5 \mathrm{~h}$ using a tropospheric $\mathrm{OH}$ concentration of $2 \times 10^{6}$ molecule $\mathrm{cm}^{-3}$. The reaction of $\mathrm{MBO}$ with $\mathrm{O}_{3}$ is relatively slow, $10.0 \times 10^{-18} \mathrm{~cm}^{3}$ molecule $\mathrm{e}^{-1} \mathrm{~s}^{-1}$, which gives a lifetime of $30 \mathrm{~h}$ at $40 \mathrm{ppb}$ ozone concentration. At present, the importance of MBO to atmospheric SOA formation is not well known, but its contribution could be significant in forested areas dominated by pine and fir trees. Recent studies have shown MBO levels as high as $6 \mathrm{ppb}$, which in some cases has exceeded that from isoprene and monoterpenes (Spaulding et al., 2003; Goldan et al., 1993).

Detection of MBO-specific reaction products in chamber and ambient field measurements is further evidence of MBO's possible influence in regions with high MBO emissions (Spaulding and Charles, 2002). Although emissions of MBO have been estimated on a global basis to be $9.6 \mathrm{Tg}$ per year, the rapid oxidation of this compound leads to contributions to $\mathrm{HO}_{\mathrm{x}}$ chemistry producing ozone, formaldehyde, acetone, and other carbonyl compounds (Steiner et al., 2007; Spaulding and Charles, 2002). In addition, dicarbonyls possibly formed through secondary reactions can lead to the increased production of SOA in an aqueous or non-aqueous aerosol phase (Carlton et al., 2007; Liggio et al., 2005; Volkamer et al., 2007; Kroll et al., 2005).

The gas-phase oxidation of MBO has been investigated in several recent laboratory studies in both the presence and absence of oxides of nitrogen $\left(\mathrm{NO}_{\mathrm{x}}\right)$. Most work to date has used smog chambers for studying the gas-phase kinetics of MBO oxidation, but in only a few cases have aerosol products been examined as well. Fantechi et al. (1998) examined the gas-phase products from the reaction of MBO with $\mathrm{OH}$ and $\mathrm{NO}_{3}$ radicals, as well as ozone. The major carbonyl products from the initial reaction were glycolaldehyde and 2hydroxy-2-methylpropanal. Additional organic products included acetone, formaldehyde, and formic acid from the $\mathrm{OH}$ and ozone reactions; acetone and organic nitrates were observed during the $\mathrm{NO}_{3}$ reaction. Alvarado et al. (1999), Noda and Ljungström (2002), and Carrasco et al. (2007) studied the oxidation of $\mathrm{MBO}$ with $\mathrm{O}_{3}$ and $\mathrm{NO}_{3}$ and found similar results. Only a single study (Chan et al., 2009) has examined aerosol formation from the irradiated MBO system in the presence and absence of $\mathrm{NO}_{\mathrm{x}}$. In that study, the photolysis of HONO served as a source of $\mathrm{OH}$ radicals in the presence of $\mathrm{NO}_{\mathrm{x}}$ and the photolysis of $\mathrm{H}_{2} \mathrm{O}_{2}$ in the absence of $\mathrm{NO}_{\mathrm{x}}$. They observed negligible SOA yields in the presence of $\mathrm{NO}_{\mathrm{x}}$ but measurable yields $(0.10-0.14 \%)$ in the absence of $\mathrm{NO}_{\mathrm{x}}$. Only a few organic reaction products were reported.

Given the uncertainties in both the emission and aerosol yields from the atmospheric oxidation of MBO, additional studies are needed to provide a more complete understanding of SOA formation from this compound. The present study examined both gas and aerosol products from MBO photooxidation. The gas-phase products were determined using both derivatization and non-derivatization techniques. Aerosol yields and other aerosol properties were evaluated in the presence and absence of $\mathrm{NO}_{\mathrm{x}}$. Moreover, a detailed examination of organic compounds comprising the aerosol was also undertaken with the intent of identifying possible unique tracer compounds in ambient aerosol. Previously described tracer methods (Kleindienst et al., 2007) were then used to determine the extent to which such compounds can be used to estimate the contribution of MBO to organic aerosol in ambient air. The levels of these tracer compounds were then evaluated from field samples. Finally, the effect of acidic sulfate aerosol was studied to determine the possible role of acidity on MBO SOA formation.

\section{Experimental methods}

\subsection{Apparatus and reactants}

The experiments were conducted in a $14.5 \mathrm{~m}^{3}$ stainlesssteel, fixed-volume chamber with walls having a 40- $\mu \mathrm{m}$ TFE Teflon coating. The chamber incorporates a combination of fluorescent bulbs to provide radiation distributed over the actinic portion of the spectrum similar to solar radiation, from 
300 to $400 \mathrm{~nm}$. For some irradiations without $\mathrm{NO}_{\mathrm{x}}$ present, UV-313 sunlamps were also used. The chamber was operated either as a conventional batch reactor or in a flow mode to produce a steady-state concentration of gas- and particlephase reaction products for experiments requiring large sampling volumes. Temperature and relative humidity within the chamber were determined with an Omega Engineering, Inc. (Stamford, CT) digital thermo-hygrometer (Model RH411). Light intensity was continuously monitored with an integrating radiometer (Eppley Laboratory, Inc., Newport, RI). Additional details of the chamber and its operation have been described by Kleindienst et al. (2006).

Experiments were conducted in either the presence or absence of $\mathrm{NO}_{\mathrm{x}}$. For experiments with $\mathrm{NO}_{\mathrm{x}}$, the photolysis of methyl nitrite $\left(\mathrm{CH}_{3} \mathrm{ONO}\right)$ was the primary initial source of hydroxyl radicals $(\mathrm{OH})$. $\mathrm{MBO}, \mathrm{CH}_{3} \mathrm{ONO}$, and $\mathrm{NO}$ were added to the chamber through flow controllers to the target concentrations. For experiments in the absence of $\mathrm{NO}_{\mathrm{x}}$, the photolysis of hydrogen peroxide $\left(\mathrm{H}_{2} \mathrm{O}_{2}\right)$ was the source of $\mathrm{OH} . \mathrm{H}_{2} \mathrm{O}_{2}$ as a $50 \%$ aqueous solution was injected with a syringe pump into a heated glass bulb where it vaporized and then was mixed rapidly by the main dilution air flow. $\mathrm{H}_{2} \mathrm{O}_{2}$ concentrations were determined by UV absorption using a conventional ozone monitor, as described previously (Kleindienst et al., 2009). For these experiments, MBO was added as described above. In some experiments, $\mathrm{SO}_{2}$ was added to the chamber as a reactant to determine the effect of acidic sulfate aerosol in the formation of submicron organic aerosol products. Ammonium sulfate seed aerosol at approximately $1 \mu \mathrm{g} \mathrm{m}^{-3}$ was also introduced into the chamber for all experiments to serve as a condensing medium for semivolatile organic products that might form.

\subsection{Gas-phase measurements}

$\mathrm{NO}$ and $\mathrm{NO}_{\mathrm{x}}$ were monitored with a TECO (Franklin, MA) oxides of nitrogen analyzer (Model 42C) with an in-line nylon filter used to prevent nitric acid from entering the analyzer. Ozone was measured with a Bendix (Lewisburg, WV) ozone monitor (Model 8002). $\mathrm{SO}_{2}$ was determined by pulsed fluorescence detection (Model 43A, TECO, Hopington, MA). Relative MBO concentrations in the inlet and within the chamber were measured in a semi-continuous fashion by gas chromatography with flame ionization detection (GC-FID).

Detailed measurements of MBO and selected carbonyls were measured using a Hewlett-Packard (HP) (Palo Alto, CA) GC-FID (Model 5890) and a HP GC-MS (Model 6890 GC, with Model 5972 MS). A fused column $(60 \mathrm{~m} \times 0.32 \mathrm{~mm}$ inner diameter $)$ with a $1-\mu \mathrm{m}$ DB-1 coating (J \& W Scientific, Folsom, CA) was used for both GC systems. Liquid nitrogen was used to preconcentrate the analyte compounds in a sampling loop. The condensed organics were then injected onto the GC column using gas-sampling valves. The GC-FID and GC-MS operating parameters have been described previously by Blunden et al. (2005).

The identification and quantification of low molecular weight carbonyl and dicarbonyl compounds (e.g. formaldehyde, acetone, glyoxal, methyl glyoxal) was achieved by derivatization with 2,4-dinitrophenyl-hydrazine (DNPH). In this technique, air samples were drawn through an impinger containing $5 \mathrm{ml}$ of a DNPH/acetonitrile solution at a rate of $0.501 \mathrm{~min}^{-1}$. Sampling times were typically $20 \mathrm{~min}$. The samples were analyzed by high-performance liquid chromatography/ultraviolet (HPLC/UV) (Smith et al., 1989). The compounds formed during the reaction were identified and quantified from the chromatogram of a known set of 16 hydrazones and dihydrazones run as an external standard. The technique also allows the concentrations of carbonyl compounds for which standards are not available to be estimated from the average molar extinction coefficient of the standard compounds. These hydrazones show a high degree of consistency, since the extinction coefficient is dependent mainly on the chromophore rather than the substituent group (Smith et al., 1989).

Higher molecular weight carbonyl and hydroxylated compounds were collected with a 60-cm, 4-channel XAD4coated annular denuder. The denuders were analyzed for organic compounds by extracting them in a $1: 1$ dichloromethane/methanol (DCM/MeOH) mixture and then derivatizing with $\mathrm{O}, \mathrm{N}$-pentafluorobenzyl hydroxylamine (PFBHA) followed by a second derivatization with bis(trimethylsilyl) trifluoroacetamide (BSTFA) (Jaoui et al., 2004). Ketopinic acid (KPA) was used as an internal standard (IS). Extracts were then analyzed by GC-MS using the techniques described below.

\subsection{Aerosol-phase measurements}

Organic carbon concentrations were measured using a semicontinuous elemental carbon-organic carbon (EC-OC) instrument (Sunset Laboratories, Tigard, OR). The instrument operates with a quartz filter positioned within the oven housing used for the analysis. The pumping system drew chamber effluent through the filter at a rate of $81 \mathrm{~min}^{-1}$. A carbonstrip denuder was placed in-line before the quartz filter to remove gas-phase organic compounds in the effluent that might interfere with the OC measurement. With a sample collection time of $0.5 \mathrm{~h}$ and an analysis time of $0.25 \mathrm{~h}$, the duty cycle for the measurement of $\mathrm{OC}$ was $0.75 \mathrm{~h}$.

Aerosol size distribution, volume, and total number density were measured with a Scanning Mobility Particle Sizer (SMPS) (Model 3071A, TSI, Inc., Shoreview, MN) and a Condensation Particle Counter (CPC) (Model 3010, TSI, Inc., Shoreview, MN). The operating conditions for the SMPS were $0.21 \mathrm{~min}^{1}$ sample flow, $21 \mathrm{~min}^{1}$ sheath flow, and 19 to $982 \mathrm{~nm}$ size scan. The SMPS was also used to determine effective enthalpies of vaporization of MBO aerosol by 
adding a heated inlet, which allows the aerosol to be subjected to a range of temperatures (Offenberg et al., 2006).

The aerosol formed in the chamber was also collected with 47-mm glass-fiber filters (Pall Gelman Laboratory, Ann Arbor, MI) for off-line analysis. Samples were collected at a flow rate of $151 \mathrm{~min}^{-1}$. These samples were then extracted by sonication with methanol. The filter extracts were then derivatized with BSTFA (Jaoui et al., 2004).

All extracts were analyzed by GC-MS on a ThermoQuest (Austin, TX) GC coupled with an ion trap mass spectrometer. The injector, heated to $270^{\circ} \mathrm{C}$, was operated in splitless mode. Compounds were separated on a $60-\mathrm{m}, 0.25-\mathrm{mm}$ i.d., RTX-5MS column (Restek, Inc., Bellefonte, PA) that had a $0.25-\mu \mathrm{m}$ film thickness. The oven temperature program started isothermally at $84^{\circ} \mathrm{C}$ for $1 \mathrm{~min}$ followed by a temperature ramp of $8^{\circ} \mathrm{C} \mathrm{min}^{-1}$ to $200^{\circ} \mathrm{C}$, followed by a 2-min hold, then a second ramp of $10^{\circ} \mathrm{C} \mathrm{min}^{-1}$ to $300^{\circ} \mathrm{C}$. The ion source, ion trap, and interface temperatures were 200, 200, and $300^{\circ} \mathrm{C}$, respectively.

\subsection{Laboratory procedures}

For the batch-mode experiments (static mode) in the absence of $\mathrm{NO}_{\mathrm{x}}$, a known amount of liquid $\mathrm{H}_{2} \mathrm{O}_{2}$ was injected into the chamber at the beginning of the experiment and allowed to stabilize for approximately $30 \mathrm{~min}$. A known amount of liquid MBO was then added to the chamber. After a 5-min mixing period, the lights were turned on starting the reaction. Samples were then taken for gas and particle constituents at sampling times appropriate for the required masses needed for analysis. For experiments in the presence of $\mathrm{NO}_{\mathrm{x}}$, the reactants were added simultaneously to the chamber. In dynamic experiments, reactants were added to the chamber continuously and the effluent was withdrawn at the same flow rate for denuder and filter collection and on-line gas and particle analysis.

The chamber was operated as a batch reactor in experiments ER-462, ER-463, and ER-567 and as a flow reactor with a nominal total flow of $601 \mathrm{~min}^{-1}$ in ER-464 and ER-465 to produce the steady-state reaction mixtures (Table 1). Some additional irradiations using $\mathrm{MBO}$ and $\mathrm{H}_{2} \mathrm{O}_{2}$ were conducted in a second chamber, but these were conducted as survey experiments only and none of the data is reported here. The ER-464 experiment was conducted in two stages by irradiating $\mathrm{MBO} / \mathrm{H}_{2} \mathrm{O}_{2}$ mixtures in the absence (ER-464a) or presence (ER-464b) of $\mathrm{SO}_{2}$ to produce acidic sulfate aerosol. Experiment ER-465 was also conducted in two stages by irradiating $\mathrm{MBO} / \mathrm{CH}_{3} \mathrm{ONO} / \mathrm{NO}$ mixtures in the absence (ER-465a) or presence (ER-465b) of $\mathrm{SO}_{2}$ to produce acidic sulfate aerosol. For these experiments, the reactant mixture at each stage was allowed to come to steady state over a period of $18-24 \mathrm{~h}$ before sampling began.
Table 1. Initial conditions for $\mathrm{MBO}$ experiments in the presence and absence of NO.

\begin{tabular}{|c|c|c|c|c|c|c|c|}
\hline Exp. ID & $\begin{array}{c}\mathrm{MBO} \\
(\mathrm{ppmC})\end{array}$ & $\begin{array}{l}\mathrm{H}_{2} \mathrm{O}_{2} \\
(\mathrm{ppm})\end{array}$ & $\begin{array}{c}\mathrm{CH}_{3} \mathrm{ONO} \\
(\mathrm{ppm})\end{array}$ & $\begin{array}{c}\text { NO } \\
(\mathrm{ppm})\end{array}$ & $\begin{array}{c}\mathrm{SO}_{2} \\
(\mathrm{ppm})\end{array}$ & $\begin{array}{c}\mathrm{T} \\
\left({ }^{\circ} \mathrm{C}\right)\end{array}$ & $\begin{array}{l}\text { RH } \\
(\%)\end{array}$ \\
\hline $\mathrm{ER}^{\mathrm{st}}-462$ & 19.0 & 18.8 & - & - & - & 21 & $<3$ \\
\hline $\mathrm{ER}^{\mathrm{st}}-463$ & 14.6 & - & - & 0.288 & - & 23 & 30 \\
\hline $\mathrm{ER}^{\mathrm{dy}}-464 \mathrm{a}$ & 18.2 & 6.6 & - & - & - & 24 & $<3$ \\
\hline $\mathrm{ER}^{\mathrm{dy}}-464 \mathrm{~b}$ & 18.2 & 6.6 & - & - & 0.210 & 24 & $<3$ \\
\hline $\mathrm{ER}^{\mathrm{dy}}-465 \mathrm{a}$ & 14.5 & - & 0.287 & 0.285 & - & 26 & 30 \\
\hline$E R^{d y}-465 b$ & 15.1 & - & 0.279 & 0.245 & 0.212 & 26 & 30 \\
\hline $\mathrm{ER}^{\mathrm{st}}-567$ & 15.4 & - & - & 0.309 & - & 22 & 28 \\
\hline
\end{tabular}

dy Dynamic (flow-mode) experiments.

st Static (batch-mode). experiments.

\subsection{Field measurements}

In addition to laboratory experiments, selected ambient $\mathrm{PM}_{2.5}$ samples were collected on either quartz or Teflonimpregnated glass-fiber filters. Field sample filters were typically Soxhlet extracted. The resulting extracts were evaporated to dryness and derivatized with BSTFA (Jaoui et al., 2004). Detailed descriptions of some of these field campaigns have been provided by Lewandowski et al. (2007, 2008) and Kleindienst et al. (2010). The focus of the field sample analysis has been to investigate the occurrence of $\mathrm{MBO}$ organic tracer compounds in ambient $\mathrm{PM}_{2.5}$.

\section{Results and discussion}

\subsection{Initial conditions}

The initial conditions for the experiments are given in Table 1. Initial MBO concentrations ranged from 14-19 ppmC. In the presence of $\mathrm{NO}_{\mathrm{x}}, \mathrm{CH}_{3} \mathrm{ONO}$ (when used) and $\mathrm{NO}$ were each approximately $0.3 \mathrm{ppm}$; relative humidities were set to approximately $30 \%$. For experiments in the absence of $\mathrm{NO}_{\mathrm{x}}, \mathrm{H}_{2} \mathrm{O}_{2}$ concentrations were approximately $19 \mathrm{ppm}$ in the static experiment and $7 \mathrm{ppm}$ in the inlet for the dynamic experiment. Each dynamic run had a second stage where $\mathrm{SO}_{2}$ was added to monitor the effect of acidic sulfate aerosol on the SOA yields and products; initial $\mathrm{SO}_{2}$ was $0.21 \mathrm{ppm}$. As noted, ammonium sulfate at approximately $1 \mu^{-3} \mathrm{~m}^{-3}$ was added to the reaction mixture to aid in secondary product condensation onto chamber aerosols.

A small amount of isoprene was detected by GC-FID at the beginning of some of the experiments, which is likely to be an artifact of $\mathrm{MBO}$ dehydration and results in isoprene formation during the injection, in the chamber, or during GC analysis (Tarvainen et al., 2005; Geron and Arnts, 2010). To evaluate the effect of temperature and humidity on $\mathrm{MBO}$, a storage study was performed under dry and humid conditions using dual 30-1 bags. Each bag was filled with $1 \mu \mathrm{l}$ of MBO and 251 of zero hydrocarbon air. $40 \mu \mathrm{l}$ of pre-purified liquid water was added to one of the bags. Samples from each 
bag were analyzed by GC-FID and GC-MS during alternating 1-h periods. The results show that MBO conversion to isoprene occurred under dry conditions, and up to 0.12 isoprene $\left(\mathrm{mol} \mathrm{mol}^{-1}\right)$ was observed under dry conditions compared to less than 0.02 under humid conditions, which is similar to the findings of Harley et al. (1998) and Lamanna and Goldstein (1999). Moreover, the analysis showed that reduction of the temperature at several component locations of the pre-concentration system reduces MBO dehydration significantly. Thus, we estimate at most (and probably much less than) $1 \%$ of MBO might have been converted to isoprene at the beginning of the dry experiments.

\subsection{Gas-phase products}

The analysis of laboratory-generated gas-phase and SOA products from MBO oxidation showed a series of organic compounds containing ketone, acidic, and/or alcoholic functional groups. Many of these compounds do not have authentic standards and some of the identifications were based on the interpretation of the mass spectra of the derivatized compounds. Thus, for compounds without authentic standards, identifications should be regarded as tentative. Detailed procedures for these approaches have been described in previous work (Jaoui et al., 2004, 2005).

\subsubsection{Time profile of products}

Figure 1a shows a standard photochemical time series of the major constituents in the batch reaction of $\mathrm{MBO}$ in the presence of $\mathrm{NO}_{\mathrm{x}}$. Concentrations of $\mathrm{MBO}, \mathrm{O}_{3}, \mathrm{NO}$, and $\mathrm{NO}_{\mathrm{x}}-\mathrm{NO}$ are shown for experiment ER-463. In the absence of a direct $\mathrm{OH}$ photolysis source such as $\mathrm{CH}_{3} \mathrm{ONO}$, the consumption of MBO commences with only a small induction time given its very large $\mathrm{OH}$ rate constant of $5.8 \times 10^{-11} \mathrm{~cm}^{3}$ molecule ${ }^{-1} \mathrm{~s}^{-1}$ (Carrasco et al., 2007). The profiles of the inorganic species show the characteristics of a standard $\mathrm{VOC} / \mathrm{NO}_{\mathrm{x}}$ irradiation.

For experiments in a batch mode, values for the SOA concentrations can also be determined from the SMPS measurements. These measurements have the advantage of having low limits of detection with reasonably good precision. SOA formation is difficult to distinguish at the beginning of the experiment involving only NO due to the presence of seed aerosol. However, once the initial NO is removed from the system due to reaction, SOA concentrations are seen to increase very slightly above the seed aerosol concentration as the ozone builds up in the chamber. This formation, while not quantifiable as a yield, is similar to that observed for monoterpene photooxidation in the presence of $\mathrm{NO}_{\mathrm{x}}$ (Jaoui and Kamens, 2001).

Of greater interest are the carbonyl compounds formed during the irradiation shown in Fig. 1b for experiment ER-467. It is clear that the carbonyl products from the $\mathrm{OH}+\mathrm{MBO}$ reaction are detected from the first DNPH
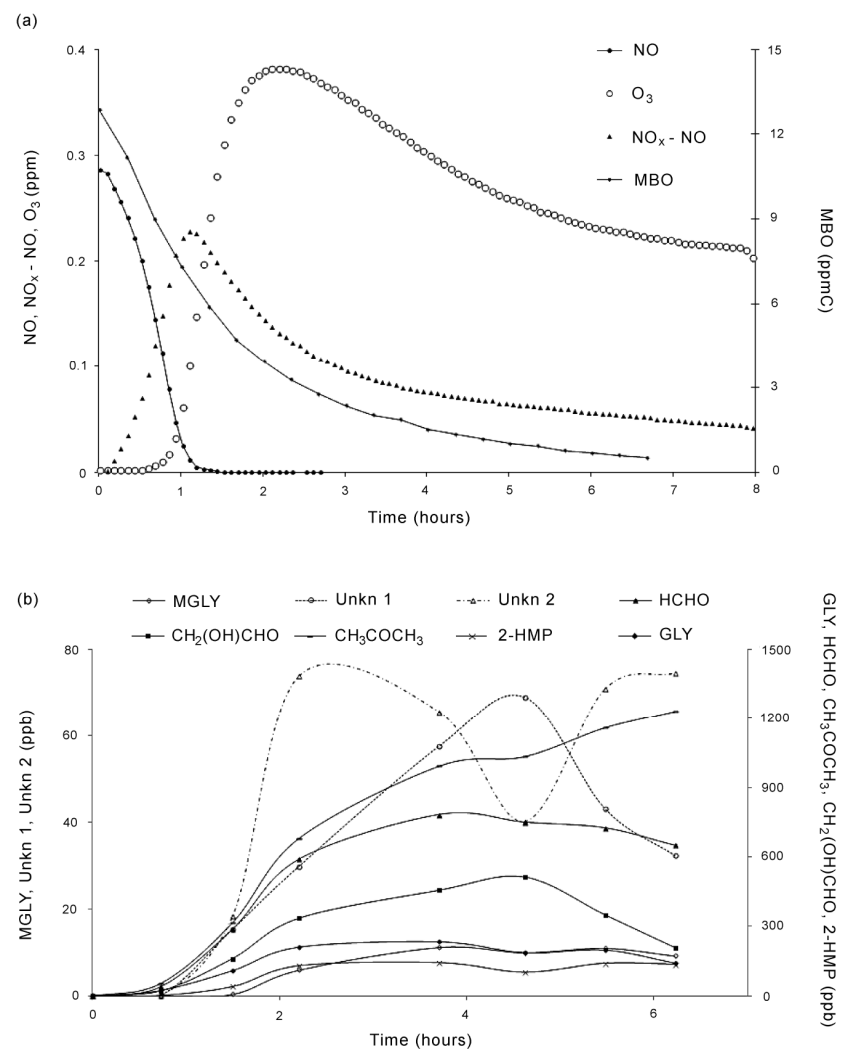

Fig. 1. Time profiles of gas-phase oxidation products from the oxidation of MBO. (a) Experiment ER-463 and (b) experiment ER467.

sample taken at $0.7 \mathrm{~h}$ with $\mathrm{NO}$ still present in the system at relatively high concentrations. According to conventional reaction kinetics, $\mathrm{OH}$ adds to the double bond in $\mathrm{MBO}$ to form an $\mathrm{RO}_{2}$ radical, which oxidizes $\mathrm{NO}$ to $\mathrm{NO}_{2}$ with the resultant alkoxy radical producing a carbonyl product. If $\mathrm{OH}$ is added to the most substituted position, scission of the alkoxy radical produces formaldehyde and 2-hydroxy-2-methylpropanal (2-HMP). While 2-HMP can be formed from $\mathrm{OH}$ addition to the most substituted position, it can also be formed from $\mathrm{OH}$ addition to the least substituted position. The carbon onto which $\mathrm{O}_{2}$ adds neighbors $\mathrm{OH}$ groups on both sides, one originally from $\mathrm{MBO}$ and the other from $\mathrm{OH}$ addition, and scission of the $\mathrm{C}-\mathrm{C}$ bond with the former leads to glycolaldehyde and acetone. However, scission of the $\mathrm{C}-\mathrm{C}$ bond with the latter leads to 2-HMP and formaldehyde. In fact, this should be the major source of 2-HMP because $\mathrm{OH}$ addition to the most substituted carbon is highly unlikely, whereas scission of the $\mathrm{CH}\left(\mathrm{O}\right.$.) $-\mathrm{CH}_{2} \mathrm{OH}$ bond is almost as likely as scission of the $\mathrm{CH}_{3} \mathrm{C}\left(\mathrm{CH}_{3}\right) \mathrm{OH}-\mathrm{CH}(\mathrm{O}$.) bond.

The elution order of the products was established from the external hydrazone standards mentioned previously. Formaldehyde and acetone formed in the reaction are clearly identified from their retention times. Hydroxycarbonyls have previously been reported (Grosjean and Grosjean, 1995) to 


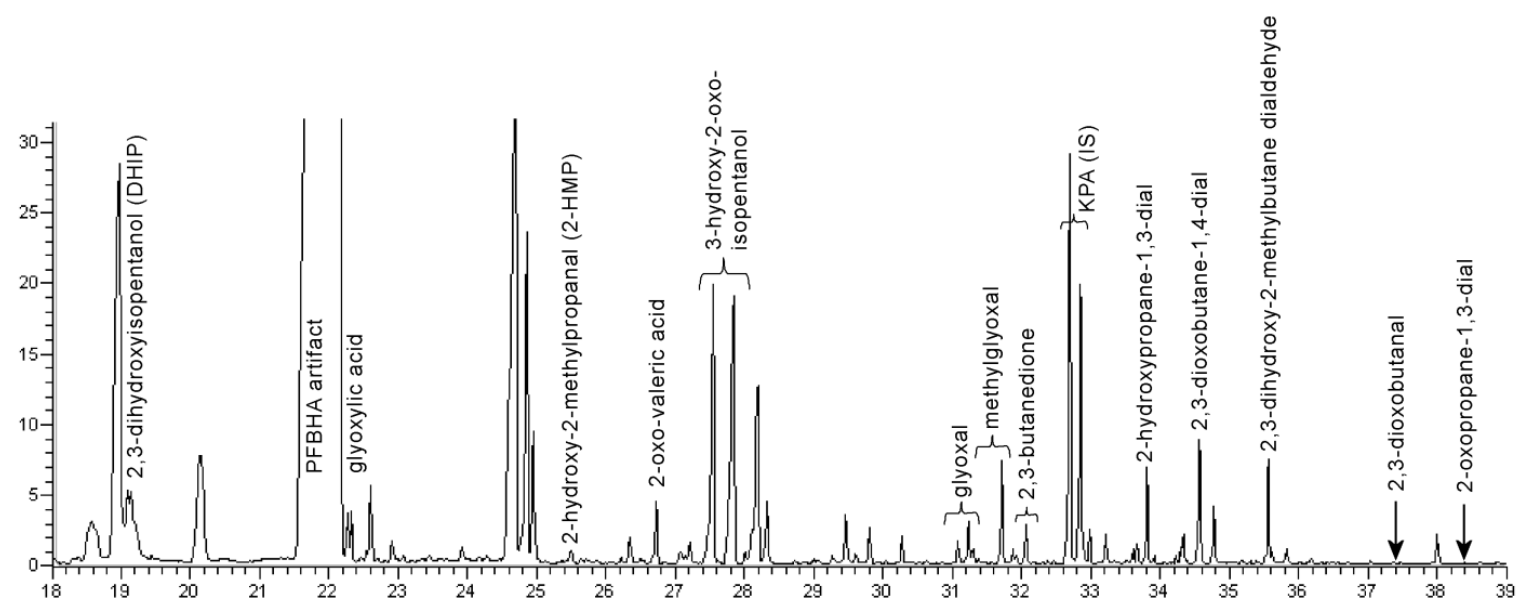

Fig. 2. GC-MS total ion chromatogram of organic extracts as PFBHA + BSTFA (gas phase) derivatives from an irradiated MBO.

have retention times that precede carbonyl compounds of the same carbon number. Thus, glycolaldehyde is detected between the hydrazones of formaldehyde and acetaldehyde and, in fact, is found to nearly co-elute with formaldehyde. Since standards are not available, the formation of 2-HMP was rationalized based on a retention time and elution order of the DNPH derivative between the formaldehyde and acetaldehyde derivatives (Grosjean and Grosjean, 1995). Under the conditions of these experiments, all of these compounds, except for acetone, have very rapid $\mathrm{OH}$ rate constants $\left(>1 \times 10^{-11} \mathrm{~cm}^{3}\right.$ molecule $\left.\mathrm{e}^{-1} \mathrm{~s}^{-1}\right)$ and thus yields for the carbonyls are very difficult to determine in the absence of secondary $\mathrm{OH}$ reaction and photolysis.

\subsubsection{Characterization of gas-phase products from denuder sampling}

A qualitative analysis was performed of the gas-phase products for experiments involving the presence or absence of $\mathrm{NO}_{\mathrm{x}}$. The analysis uses the PFBHA + BSTFA double derivatization of a denuder extract. While this technique is an integrated technique that requires long sampling times, it does provide a sensitive method for measuring low concentrations of highly oxidized organic compounds, possibly semivolatile compounds in the gas phase. Thus, products found by this collection technique could be informative for possible precursors for the types of compounds that may form in the particle phase. However, for light organics, even those that are polar, the XAD4-coated denuder acts as a chromatograph, and low molecular weight carbonyl compounds tend to elute from the denuder during the course of an extended collection.

Figure 2 shows a GC-MS chromatogram from a MBO photooxidation in the absence of $\mathrm{NO}_{\mathrm{x}}$ (ER-462). Several major peaks were detected in the gas phase including 2,3-butanedione; 2,3-dioxobutanal; 2-oxopropane-1,3dial; 2-hydroxypropane-1,3-dial; 2,3-dioxobutane-1,4-dial; 2,3-dihydroxy-2-methylbutane dialdehyde; glyoxal; and methylglyoxal. While formaldehyde, acetone, glycolaldehyde, and 2-HMP have been previously reported (see above; also Fantechi et al., 1998; Alvarado et al., 1999; Chan et al., 2009), the aldehydic compounds are highly reactive and are not detected at high concentrations by this technique at this stage of the reaction. With that stated, 2-HMP was identified based on an interpretation of the mass spectrum of a peak at a retention time of $25.5 \mathrm{~min}$, although at very low abundances. Its mass spectrum shows fragments $\left(M^{+}+1\right.$, $\left.M^{+} .-15, M^{+}-89\right)$ similar to those fragments reported in the literature by Spaulding and Charles (2002). 2-HMP has been reported in chamber and ambient atmospheres at a low ppb mixing ratio (Spaulding et al., 2003; Spaulding and Charles, 2002; Kim et al., 2010) and has been used as evidence of the contribution of MBO oxidation in mainly forested atmospheres. In our study, chamber 2-HMP by the double derivative was detected at low levels, due in large part to the extensive degree of oxidation mainly through $\mathrm{OH}$ reaction and/or by photolysis. The reaction of 2-HMP leads to the formation of formaldehyde, acetone, and possibly methylglyoxal (e.g. Fantechi et al., 1998; Spaulding et al., 2003). In addition to these compounds, several highly oxidized hydroxyl/oxo/aldehydes were identified in this study and are presented at the end of Table 2.

\subsection{Particle-phase products}

\subsubsection{Aerosol parameters}

The production of aerosol was found to be highly dependent on the exact conditions under which the experiments were carried out, in particular the presence of $\mathrm{NO}_{\mathrm{x}}$ in the system. This system produced only very low levels of aerosol, which was typically insufficient (using standard procedures for aerosol quantification) for determining aerosol parameters and detailed organic analysis. Except for a minor organic 
Table 2a. SOA and gas-phase compounds identified in the present study. For the particle phase the MW of the BSTFA derivative is given, and for the gas phase the MW of the underivatized compound is given. Methyltetrols were also detected in isoprene SOA.

\begin{tabular}{|c|c|c|c|c|}
\hline \multicolumn{5}{|c|}{ Particle phase } \\
\hline ID & $\begin{array}{c}\mathrm{Rt} \\
(\mathrm{min})\end{array}$ & $\begin{array}{l}\text { MW } \\
\text { (amu) }\end{array}$ & $\begin{array}{l}m / z \text { (methane-CI) BSTFA or } \\
\text { PFBHA + BSTFA derivative }\end{array}$ & Tentative ID \\
\hline 1 & 11.19 & $248_{\mathrm{d}}$ & $205(100), 233,131,73,249$ & - \\
\hline 2 & 11.74 & 315 & 73(100), 300, 316, 344, 356 & - \\
\hline 3 & 11.85 & - & $233(100), 73,233,159,247$ & - \\
\hline 4 & 12.34 & - & $231(100), 73,245,157,289$ & - \\
\hline 5 & 13.11 & - & $168(100), 196,208,96,73$ & - \\
\hline 6 & 13.38 & 174 & $159(100), 73,80,175,203$ & - \\
\hline 7 & 13.65 & - & $242(100), 73,300,411,427$ & - \\
\hline 8 & 13.89 & - & $315(100), 389,227,343,73$ & Sulfuric acid/ammonium sulfate \\
\hline 9 & 14.09 & - & $207(100), 80,73,322,295$ & - \\
\hline 10 & 14.20 & - & $406(100), 390,420,221,73$ & - \\
\hline 11 & 14.29 & - & $73(100), 189,117,233,249$ & - \\
\hline 12 & 14.66 & - & 221(100), 390, 73, 406, 336 & - \\
\hline 13 & 14.84 & - & $73(100), 316,332,177,221$ & - \\
\hline 14 & 14.97 & - & $73(100), 277,131,189,247$ & - \\
\hline 15 & 15.93 & - & $73(100), 179,265,293,59$ & - \\
\hline 16 & 16.26 & 348 & $73(100), 131,189,277,349$ & - \\
\hline 17 & 16.59 & - & 196(100), 180, 73, 73, 247 & - \\
\hline 18 & 17.34 & - & $374(100), 73,189,389,284$ & - \\
\hline 19 & 17.50 & - & $73(100), 131,173,189,247$ & - \\
\hline 20 & 18.29 & 336 & $231(100), 247,157,191,321$ & 2,3-Dihydroxyisopentanol \\
\hline 21 & 18.45 & 334 & $319(100), 334,229,245,73$ & 3-Hydroxy-2-oxoisopentanol \\
\hline 22 & 18.83 & - & $73(100), 221,281,330,443$ & - \\
\hline 23 & 18.92 & - & $73(100), 430,272,217,386$ & - \\
\hline 24 & 19.34 & 350 & $73(100), 189,205,247,117$ & 1,2,3-Trihydroxy-3-methylbutanal \\
\hline 25 & 19.79 & 350 & $217(100), 335,73,277,291$ & 2-Hydroxy-2-methylpropanedioic acid \\
\hline 26 & 20.8 & 313 & $298(100), 73,221,268,342$ & - \\
\hline 27 & 20.75 & - & $159(100), 73,117,175,247$ & - \\
\hline 28 & 20.86 & - & $159(100), 73,117,175,247$ & - \\
\hline 29 & 21.51 & - & $159(100), 73,117,175,247$ & - \\
\hline 30 & 21.64 & - & $238(100), 159,222,73,142$ & - \\
\hline 31 & 22.05 & - & $73(100), 231,157,191,247$ & - \\
\hline 32 & 22.18 & - & $73(100), 231,157,191,247$ & - \\
\hline 33 & 22.30 & - & $296(100), 206,132,222,312$ & - \\
\hline 34 & 22.68 & 254 & $165(100), 239,255,283,295$ & Ketopinic acid (IS) \\
\hline 35 & 23.27 & 424 & 409(100), 219, 319, 293, 203 & 2-Methylerythritol \\
\hline 36 & 23.41 & - & $205(100), 73,265,221,131$ & - \\
\hline 37 & 23.54 & - & $73(100), 201,275,175,80$ & - \\
\hline 38 & 23.73 & 424 & 409(100), 219, 319, 293, 203 & 2-Methylthreitol \\
\hline 39 & 24.88 & 276 & 73(100), 131, 191, 205, 261 & 2,3-Dihydroxy-2-methylbutane dialdehyde \\
\hline 40 & 25.23 & - & 73(100), 219, 117, 231, 189 & - \\
\hline 41 & 25.31 & - & $73(100), 231,159,205,305$ & - \\
\hline 42 & 25.40 & - & $73(100), 231,159,205,305$ & - \\
\hline 43 & 25.49 & - & 73(100), 131, 191, 291, 215 & - \\
\hline 44 & 25.67 & 452 & $437(100), 319,335,203,481$ & 2,3-Dihydroxy-2-methylsuccinic acid and isomers \\
\hline 45 & 25.81 & - & $73(100), 131,191,291,215$ & - \\
\hline 46 & 25.97 & 452 & $437(100), 319,335,203,481$ & 2,3-Dihydroxy-2-methylsuccinic acid and isomers \\
\hline 47 & 26.13 & - & $73(100), 231,157,177,247$ & - \\
\hline 48 & 26.40 & - & $205(100), 73,231,333,407$ & - \\
\hline 49 & 26.98 & - & $157(100), 73,231,247,379$ & - \\
\hline 50 & 27.07 & - & 73(100), 275, 335, 393, 177 & - \\
\hline 51 & 27.58 & - & 73(100), 231, 117, 205, 293 & - \\
\hline 52 & 28.01 & - & $73(100), 157,247,219,131$ & - \\
\hline
\end{tabular}


Table 2b. Continued.

\begin{tabular}{lrrll}
\hline \multicolumn{5}{c}{ Gas phase } \\
\hline ID & $\begin{array}{r}\text { Rt } \\
(\mathrm{min})\end{array}$ & $\begin{array}{c}\text { MW } \\
(\mathrm{amu})\end{array}$ & $\begin{array}{l}m / z \text { (methane-CI) BSTFA or } \\
\text { PFBHA + BSTFA derivative }\end{array}$ & Tentative ID \\
\hline 53 & - & 30 & - & Formaldehyde \\
54 & - & 44 & - & Acetaldehyde \\
55 & - & 58 & - & Acetone \\
56 & 31.08 & 58 & $449(100), 181,477,489,521$ & Glyoxal \\
57 & - & 60 & - & Glycolaldehyde \\
58 & 31.71 & 72 & $463(100), 491,181,445,265$ & Methylglyoxal \\
59 & 22.71 & 74 & $342(100), 382,326,73,370$ & Glyoxylic acid \\
60 & 32.06 & 86 & $477(100), 181,505,279,459$ & 2,3-Butanedione \\
61 & 38.19 & 86 & $672(100), 700,181,642,111$ & 2-Oxopropane-1,3-dial \\
62 & 25.50 & 88 & $266(100), 310,338,181,364$ & 2-Hydroxy-2-methylpropanal \\
63 & 33.80 & 88 & $563(100), 291,251,489,181$ & 2-Hydroxypropane-1,3-dial \\
65 & 37.48 & 100 & $686(100), 488,714,181,776$ & 2,3-Dioxobutanal \\
66 & 34.55 & 114 & $505(100), 266,181,533,545$ & 2,3-Dioxobutane-1,4-dial \\
$*$ & 27.53 & 118 & $442(100), 73,368,294,486$ & 3-Hydroxy-2-oxo-isopentanol \\
$*$ & 27.82 & 118 & $442(100), 352,368,233,73$ & 2,3-Dihydroxy-3-methylbutanal \\
67 & 35.57 & 132 & $593(100), 503,536,621,354$ & 2,3-Dihydroxy-2-methylbutane dialdehyde \\
68 & 26.73 & 116 & $294(100), 368,384,412,73$ & 2-Oxovaleric acid \\
\hline
\end{tabular}

nitrate channel, the photooxidation system in the presence of $\mathrm{NO}_{\mathrm{x}}$ converts virtually all $\mathrm{RO}_{2}$ formed into $\mathrm{RO}$ radicals, which then decompose or isomerize to produce carbonyl or hydroxycarbonyl compounds (Atkinson, 2000). Without $\mathrm{NO}_{\mathrm{x}}$ in the system, $\mathrm{RO}_{2}$ radicals typically react with $\mathrm{HO}_{2}$ or self-react to produce a product molecule with five carbons while adding functional groups to the product. These products are sufficiently nonvolatile to condense into the particle phase, and the system without $\mathrm{NO}_{\mathrm{x}}$ was the only one where aerosol parameters and composition were measured.

The secondary organic aerosol $\left(Y_{\mathrm{SOA}}\right)$ and secondary organic carbon $\left(Y_{\mathrm{SOC}}\right)$ yields are generally defined using the following relationships: $Y_{\mathrm{SOA}}=\mathrm{SOA} / \Delta \mathrm{HC}$ and $Y_{\mathrm{SOC}}=\mathrm{SOC} / \Delta \mathrm{HC}_{\mathrm{C}}$, where $\mathrm{SOC}$ is the corrected organic carbon concentration, $\triangle \mathrm{HC}$ is the reacted hydrocarbon mass concentration, and $\triangle \mathrm{HC}_{\mathrm{C}}$ is the reacted carbon mass concentration of the hydrocarbon obtained from Table 3. SOA was obtained from gravimetric measurement of the filter when the total aerosol mass was predominantly $\mathrm{SOA}$ (i.e. non- $\mathrm{SO}_{2} \mathrm{ex}-$ periments). Organic carbon and organic aerosol yields were determined for some experiments where the chamber was operated in a dynamic mode. Uncertainties in the yields come from the experimental uncertainties in SOA and the reacted MBO concentrations.

Yields were not calculated for the static experiments because the long sampling times produced very high dilution correction. Yields for dynamic experiments conducted in this study are reported in Table 3. Note that no measurable yield for experiment ER-465a was obtained. The SOA yield was also found to be $0.7 \%$ for the system in the absence of $\mathrm{NO}_{\mathrm{x}}$ (ER-464a). However, in some experiments conducted in the presence of $\mathrm{H}_{2} \mathrm{O}_{2}$ with and without acidic sulfate aerosol (ER-464a, b and ER-465b), organic aerosol was formed and measured using the carbon analyzer with carbon yields $\left(Y_{\mathrm{SOC}}\right)$ ranging from $0.2 \%$ to $0.9 \%$. For all experiments with $\mathrm{MBO}$, the yield tended to be systematically higher for experiments conducted under acidic conditions, particularly under high $\mathrm{NO}_{\mathrm{x}}$ conditions. The implications of these findings are discussed below.

The yield results obtained in this study are different than those reported by Chan et al. (2009). While it is not expected that different experimental chambers provide identical results, under high $\mathrm{NO}_{\mathrm{x}}$ conditions the yield data reported here agree with Chan et al. (2009) and show that aerosol formation is negligible, but yields under low $\mathrm{NO}_{\mathrm{x}}$ vary by an order of magnitude, even under similar seed conditions. The one difference between the two studies under low $\mathrm{NO}_{\mathrm{x}}$ conditions is the relative MBO concentrations. The MBO concentrations in this study are a factor of 100 higher, while the $\mathrm{H}_{2} \mathrm{O}_{2}$ concentrations are about the same. This suggests that the branching between $\mathrm{RO}_{2}+\mathrm{RO}_{2}$ and $\mathrm{RO}_{2}+\mathrm{HO}_{2}$ is different between the two studies (Kleindienst et al., 2009). Since DHIP is a product of $\mathrm{RO}_{2}+\mathrm{RO}_{2}$ reactions, this may explain why DHIP, and the overall aerosol formation, is higher in this study. Another possible explanation is the organic loading. Semivolatile partitioning is nonlinear, and once saturation is reached, partitioned organics can induce more condensation into the organic phase. Here, it is plausible that MBO was present in high enough concentrations for semivolatile products to overcome saturation, and hence the organic loading 
Table 3. OM/OC ratio and SOA and SOC yields. SOA yields could not be calculated for runs involving $\mathrm{SO}_{2}$ because the filter masses consisted of both SOA and inorganic sulfate, and inorganic sulfate mass concentrations were not independently measured.

\begin{tabular}{cccccccc}
\hline Exp. ID & $\begin{array}{c}\text { Reacted MBO } \\
\left(\mu \mathrm{g} \mathrm{m}^{-3}\right)\end{array}$ & $\begin{array}{c}\text { Reacted MBO } \\
\left(\mu \mathrm{g} \mathrm{m}^{-3}\right)\end{array}$ & $\begin{array}{c}\text { Aerosol } \\
\left(\mu \mathrm{g} \mathrm{m}^{-3}\right)\end{array}$ & $\begin{array}{c}\mathrm{SOC} \\
\left(\mu \mathrm{C} \mathrm{m}^{-3}\right)\end{array}$ & OM/OC & $\begin{array}{c}Y_{\text {SOA }} \\
(\%)\end{array}$ & $\begin{array}{c}Y_{\text {SOC }} \\
(\%)\end{array}$ \\
\hline ER-464a & 4967 & 3465 & 32.5 & 15.5 & 2.1 & 0.7 & 0.5 \\
ER-464b & 5994 & 4182 & 74.1 & 37.6 & - & - & 0.9 \\
ER-465a & 10336 & 7211 & Negligible & Negligible & - & - & - \\
ER-465b & 10623 & 7411 & 138.0 & 12.3 & - & - & 0.2 \\
\hline
\end{tabular}
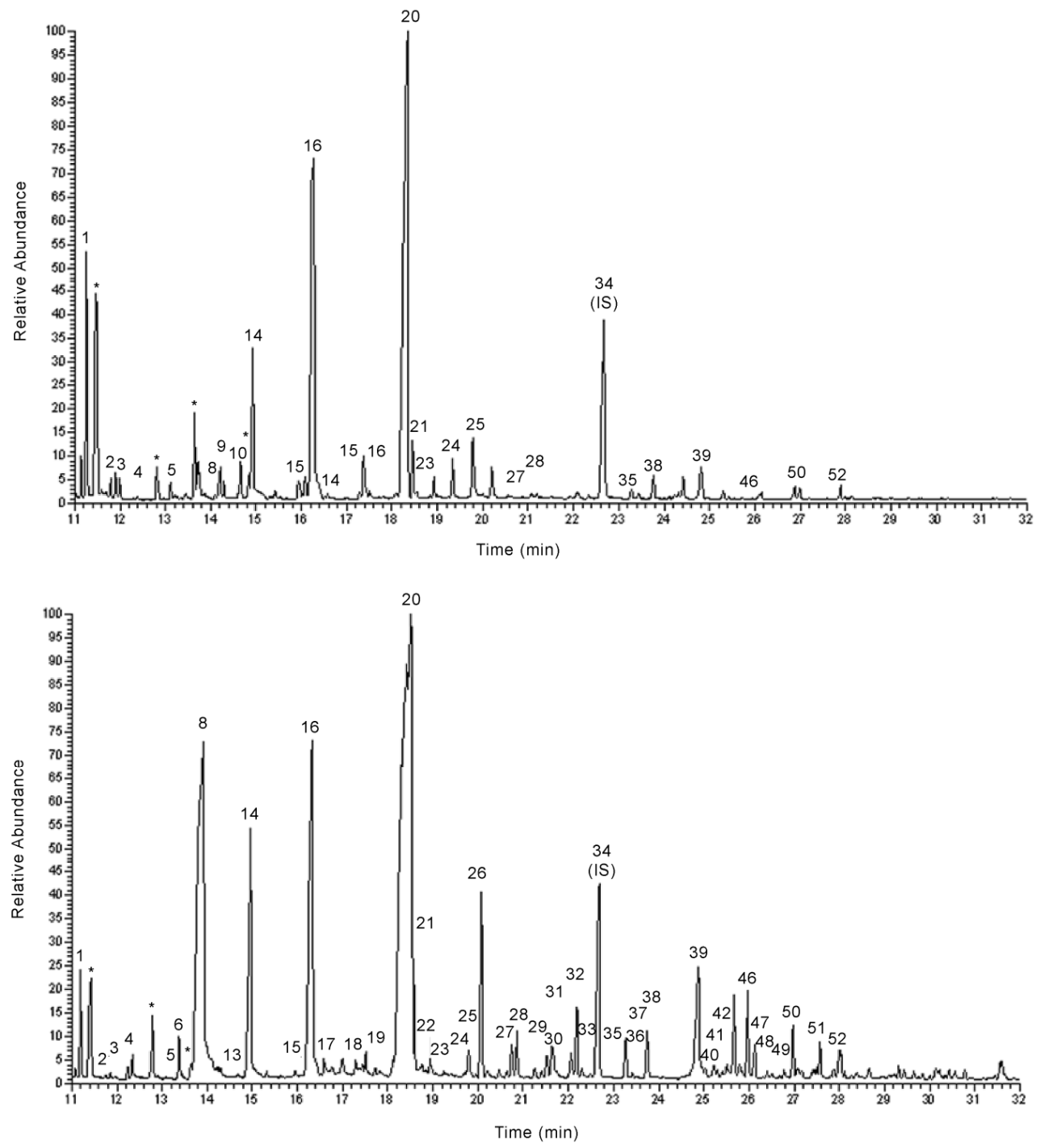

Fig. 3. GC-MS total ion chromatogram of organic extracts as BSTFA derivatives for particle-phase products from the photooxidation of $\mathrm{MBO}$ in the absence (top) and presence (bottom) of acidic sulfate aerosol. 
(a) 2,3-dihydroxyisopentanol (20: DHIP) (EI mode)
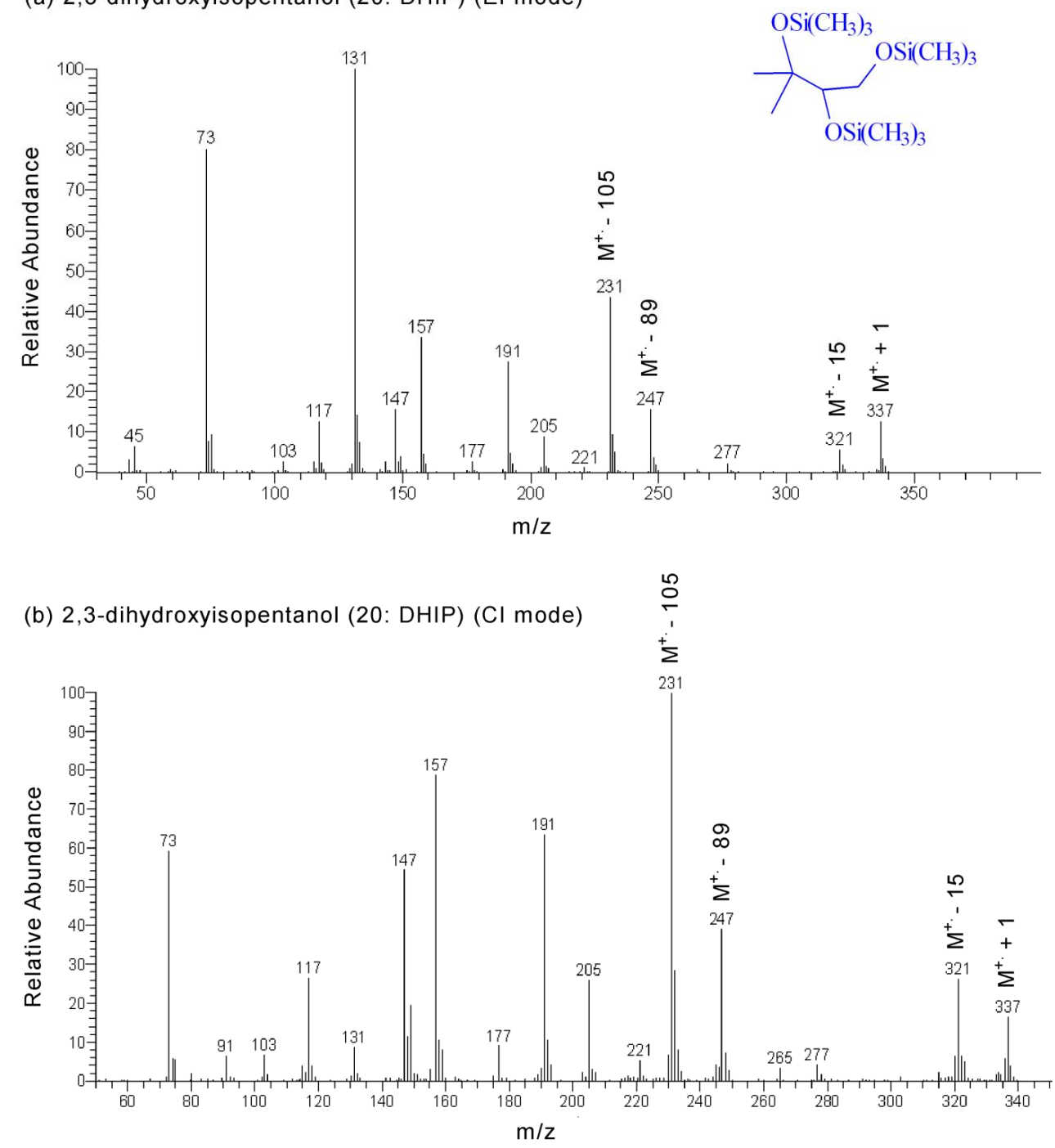

Fig. 4. EI (a) and CI (b) mass spectra of the BSTFA derivative of 2,3-dihydroxyisopentanol (20).

became high enough for these semivolatiles to condense. In this case, the results from the present work are more relevant to the ambient atmosphere, in which an organic phase is always present for sub-saturated semivolatiles to condense.

\subsubsection{Characterization of SOA products}

Sufficient aerosol masses collected on glass-fiber (GF) filters from the experiments were analyzed by GC-MS. The total ion chromatogram (TIC) is shown in Fig. 3 for cases without (top) and with (bottom) $\mathrm{SO}_{2}$ for an irradiation of $\mathrm{MBO}$ using the photolysis of $\mathrm{H}_{2} \mathrm{O}_{2}$ as the source of $\mathrm{OH}$ radicals. Mass spectra from the TIC show the presence of more than 60 derivatized compounds (not all labeled) in the absence of $\mathrm{NO}_{\mathrm{x}}$. In some cases, semivolatile compounds presumably have been detected both in the gas and particle phases. The approach used for identifying individual product compounds is as follows: all chromatograms were blank corrected for peaks found in blank or background extracts. An identification number was then associated with each remaining peak only if its corresponding mass spectrum was consistent with the fragmentation pattern of a derivatized analyte (Jaoui et al., 2005) and any underivatized compounds were not considered. All recorded spectra were compared with spectra derived from reference compounds obtained from various sources including authentic standards, previous reports of a compound with the same nominal mass spectrum, detection in the field samples, and finally an interpretation of the mass spectrum solely. Such a procedure was employed previously by Edney et al. (2003).

The GC-MS analysis shows the presence of several significant peaks (e.g. 8, 14, 16, 20, 26, 36, 38, 39, 42, 46) 
(a) El mode
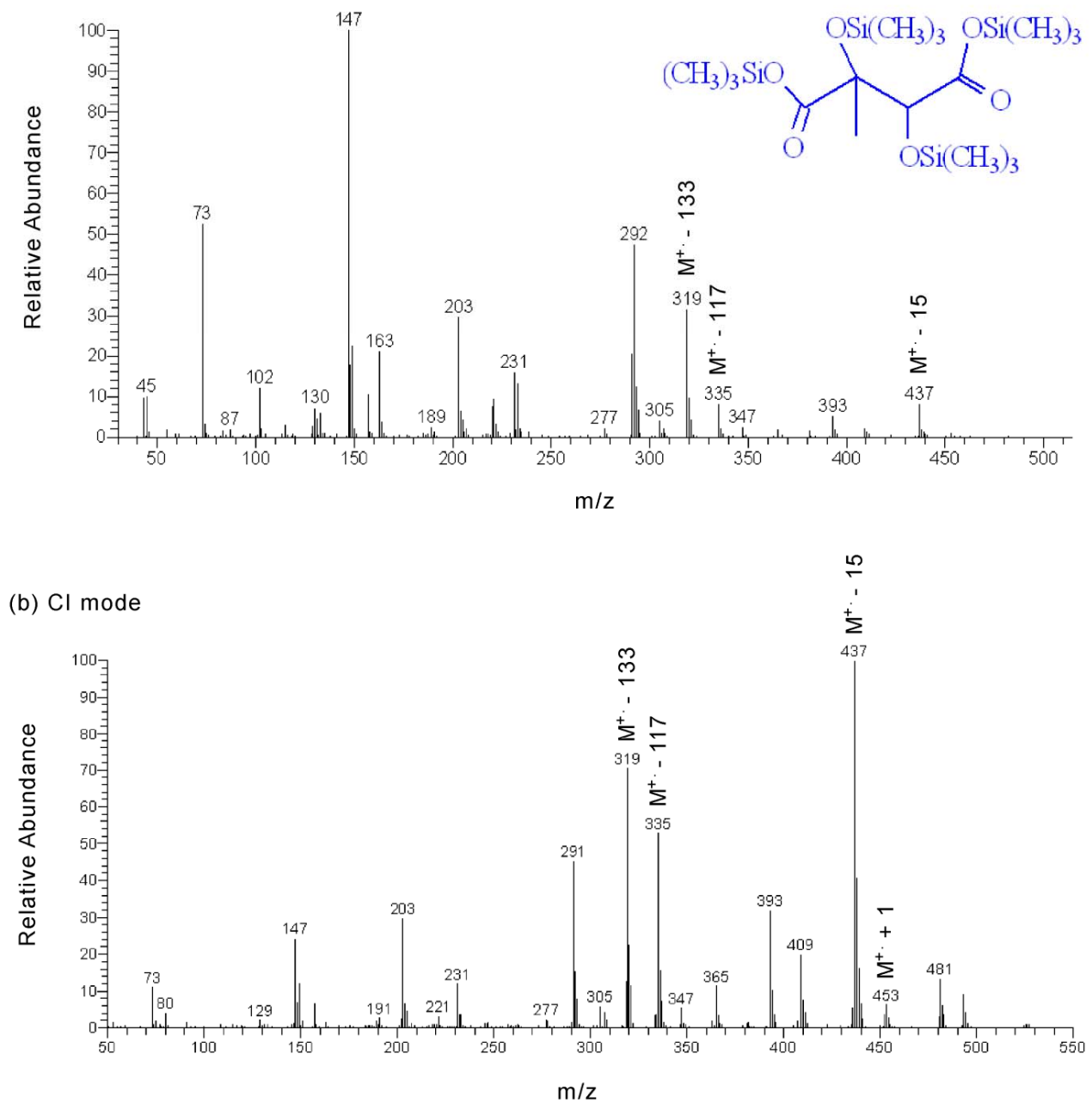

Fig. 5. Mass spectra of (42 and 46 from Fig. 3) tentatively identified as 2,3-dihydroxy-2-methylsuccinic acid.

in the particle phase. In addition, a large number of smaller peaks were observed in the gas and particle phases, reflecting the complexity of the oxidation of MBO. Additional compounds (e.g. high molecular weight organics, organonitrates, organosulfates) could have been present in the SOA or the gas phase but could not be detected based on the analytical techniques used in this study. To facilitate discussion, compounds identified in the present study are listed in Table 2 along with their retention times, molecular weights (MWs) of the derivatized compounds (when possible), and the mass fragments/adducts $(\mathrm{m} / \mathrm{z})$ of the derivatives. A tentative identification for some compounds was also included in Table 2.

SOA generated from MBO oxidation is dominated by oxygenated compounds in which MBO double bonds are oxidized. The GC-MS analysis of TIC data for SOA from the oxidation of $\mathrm{MBO}$ in the presence of $\mathrm{H}_{2} \mathrm{O}_{2}$ and $\mathrm{SO}_{2}$ (ER464b) shows the presence of eight significant peaks $(8,14$, $16,20,22,39,42$, and 46) in the SOA. By far, the largest peak detected was that associated with compound 20 of parent mass $\mathrm{m} / \mathrm{z} 336$ eluted here at $18.5 \mathrm{~min}$. Compound 20 is the predominant peak in the particle-phase extract but was also detected to a minor degree in the gas phase. This compound was the largest peak in all experiments conducted in this study involving $\mathrm{NO}_{\mathrm{x}}, \mathrm{H}_{2} \mathrm{O}_{2}$, or $\mathrm{SO}_{2}$.

Figure 4 shows both the EI (top) and CI (bottom) mass spectra of the compound 20 BSTFA derivative. The CI mass spectrum of this compound shows characteristic fragment ions at $m / z 231\left(M^{+}-105\right), 247\left(M^{+} \cdot-89\right)$, and $321\left(M^{+} \cdot 15\right)$, and adducts at $M^{+\cdot}+1, M^{+\cdot}+29$, and $M^{+\cdot}+41$. These fragments and adducts are consistent with the presence of three $(-\mathrm{OH})$ groups and a MW of the derivatized compound $\left(M_{\mathrm{d}}\right)$ of 336 dal (all masses hereafter given as daltons) and compound $\mathrm{MW}\left(M_{\mathrm{c}}\right)$ of 120 . In addition, the absence of an $m / z 219\left(M^{+}-117\right)$ peak suggests the absence of an organic acid group in the compound. The EI spectrum of compound 20 shows fragments at $m / z 73,131$, 

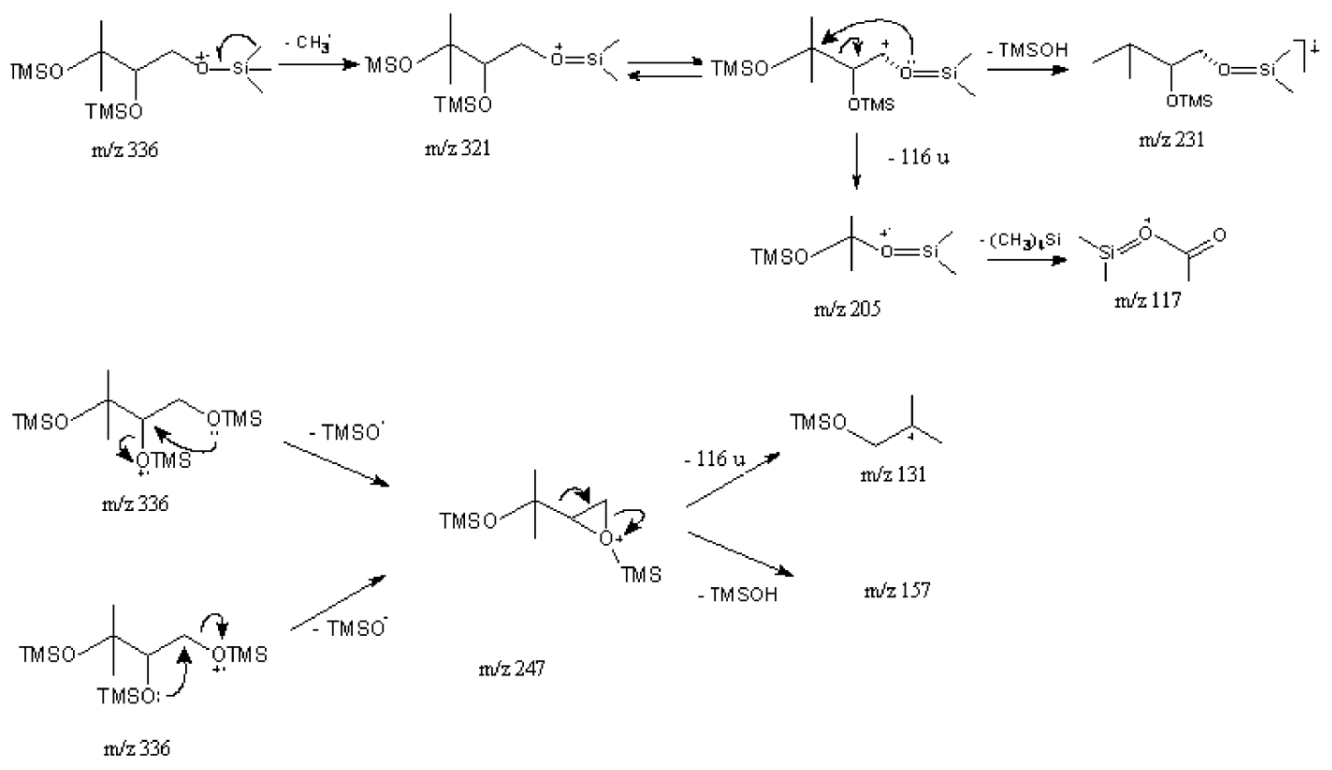

Scheme 1. Proposed fragmentation pathways for silylated compound 20 in EI mode.

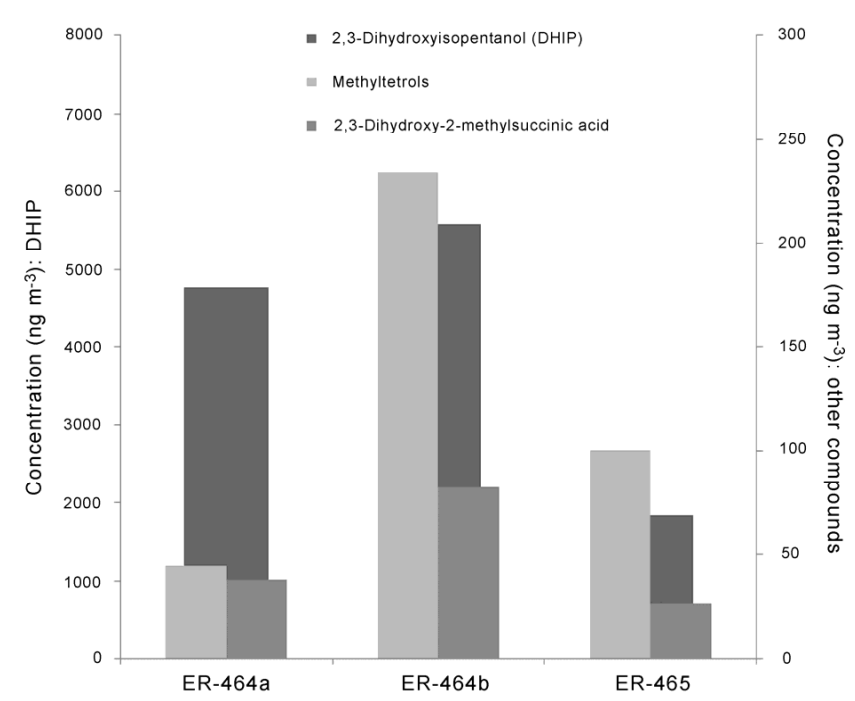

Fig. 6. Concentrations $\left(\mathrm{ng} \mathrm{m}^{-3}\right)$ of DHIP, methyltetrols (2-methylerythritol + 2-methylthreitol), and 2,3-dihydroxy-2methylsuccinic acid as KPA.

231, 321, and 337 (Fig. 4a), again consistent with the presence of three (-OH) groups, giving an $M_{\mathrm{d}}$ of 336 and an $M_{\mathrm{c}}$ of 120. The mass spectra of BSTFA derivatives of compound 20 , erythrose, and 2-methylglyceric acid (2-MGA) are similar, but each compound elutes at a different retention time and has a fragmentation pattern sufficiently different from compound 20 to distinguish the individual compounds. This is readily seen from an examination of the mass spectrum of erythrose formed from the oxidation of 1,3-butadiene (Angove et al., 2006; Jaoui et al., 2012).
The interpretation of the fragmentation patterns of the BSTFA derivative in EI mode is shown in Scheme 1. Fragment ions at $\mathrm{m} / \mathrm{z}, 117,131,157,205,231,247$, and 321 in Scheme 1 are postulated to come from loss of one or more groups including $\left(-\mathrm{CH}_{3}\right),(-\mathrm{TMSOH}),\left(-\left(\mathrm{CH}_{3}\right)_{4} \mathrm{Si}\right)$, $(-116 \mathrm{u})$, and (-TMSO). The base peak at $m / z 131$, for example, is possibly formed by a combined loss of (-TMSO) and $(-116 \mathrm{u})$ groups from the molecular ion $\mathrm{M}^{+}$, with elimination of (-TMSO) leading to the formation of a fragment at $m / z 247$. Thus, compound 20 has been tentatively identified as 2,3-dihydroxyisopentanol (DHIP; see Table 2) and was also detected to a very minor degree in the gas phase (Fig. 2).

Figure 5 shows mass spectra in the EI (top) and CI (bottom) modes for two additional silylated compounds eluting at 25.5 and $26 \mathrm{~min}$ (Fig. 3, peaks 42 and 46 ). The silylated derivative analyzed in CI mode shows fragments at $m / z 437$ $\left(M^{+\cdot}-15\right), 319\left(M^{+\cdot}-133\right)$, and $335\left(M^{+}-117\right)$, and generally weak adducts at $M^{+\cdot}+1, M^{+\cdot}+29$, and $M^{+}+41$. Fragmentation patterns of the silylated compound are similar in CI and EI modes and are consistent with the presence of four - $\mathrm{OH}$ groups, with a derivative MW of 452. This compound was the most oxygenated product detected in MBO and tentatively identified as 2,3-dihydroxy-2-methylsuccinic acid (or isomers) with a compound MW of 164 . This compound has also been detected in the particle phase in field samples (Edney et al., 2003) and from the photooxidation of toluene and 1,3,5-trimethylbenzene.

Although 2-methylthreitol and 2-methylerythritol are found to originate from isoprene oxidation, these compounds were also detected during the oxidation of MBO (Fig. 3, peaks 36 and 38). However, 2-methyl glyceric acid 
(a): DHIP (20) in chamber experiment ( $\mathrm{Cl}$ mode)

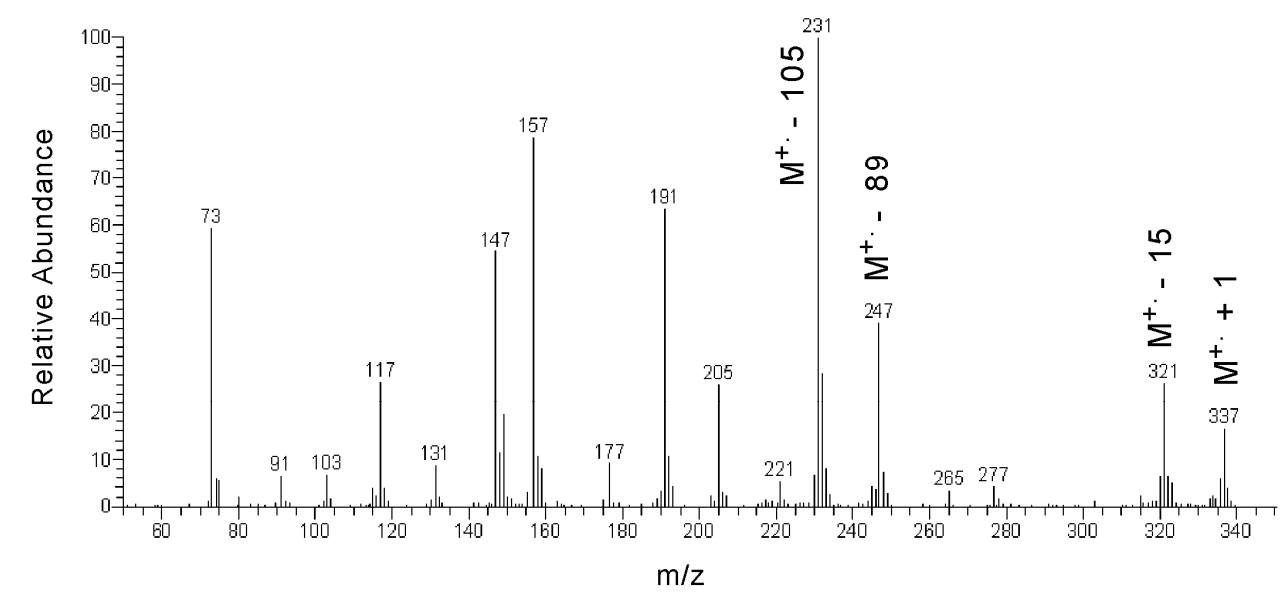

(b): DHIP (20) in ambient samples ( $\mathrm{Cl}$ mode)

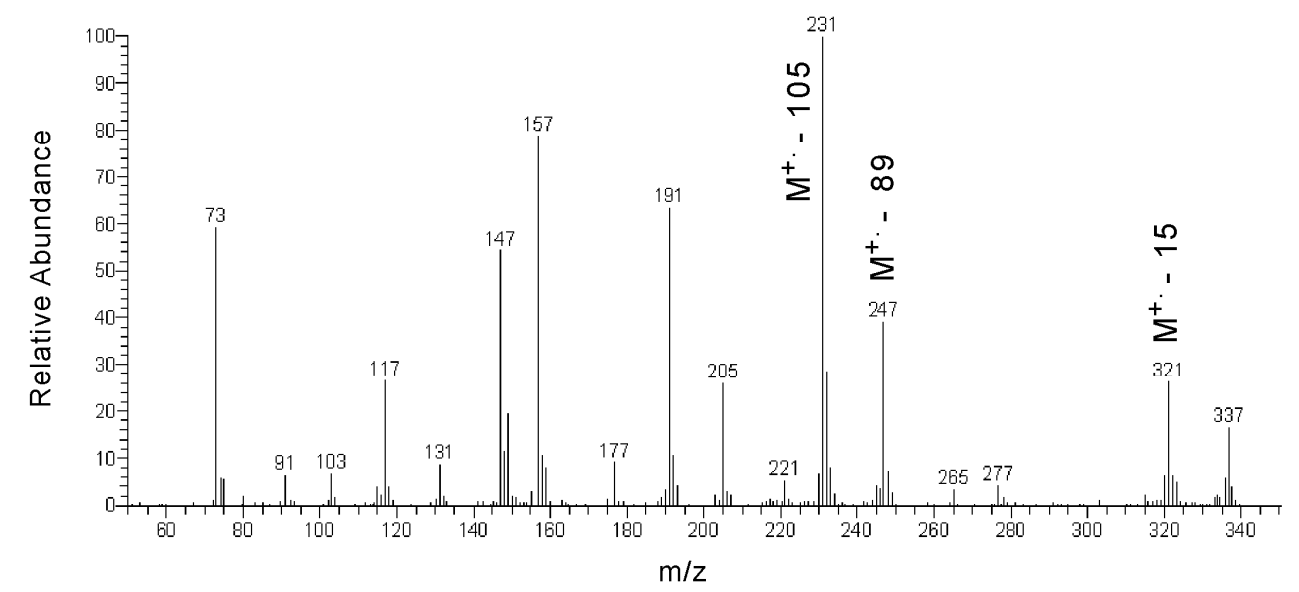

Fig. 7. Mass spectrum of the BSTFA derivative of DHIP (20) in CI mode observed in a chamber experiment (a) and in ambient samples (b).

(2-MGA), which is seen in aerosol from isoprene photooxidation, is just barely detectable above the chromatographic background and may have been formed from a slight isoprene impurity in the MBO. Given the extremely small abundance of 2-MGA in these laboratory samples, it is unlikely this compound from MBO contributes measurably to aerosol collected under ambient conditions, especially where DHIP is very low. Given this assumption, it is relatively easy to determine the origin of the methyltetrols in ambient samples by examining the co-presence of 2-MGA or DHIP.

Other compounds identified in the particle phase include oxalic acid, 3-hydroxy-2-oxo-isopentanol/2,3-dihydroxy3-methylbutanal, 2,3-trihydroxy-3-methylbutanal, 2hydroxy-2-methylpropanedioic acid, and 2,3-dihydroxy-2methylbutane dialdehyde. While compound names have been provided in Table 2, structural isomers having the same set of derivative adducts or fragments are also possible, and thus the names might be ambiguous.
SOA products from the BSTFA derivatization have been quantified in the MBO system using the KPA calibration method (Jaoui et al., 2004, 2005), since authentic standards are not available for these compounds. The detection limit of a series of organic compounds, including KPA, was determined previously by Jaoui et al. (2004). By this technique, the integrated TIC of the compound of interest is determined against the TIC of KPA. The accuracy of this approach has previously been discussed and has been found to be on the order of $60 \%$ for an oxygenated diacid such as pinic acid. Compound abundances for DHIP, methyltetrols, and 2,3dihydroxy-2-methylsuccinic acid were thus determined by this method for experiments ER-464 and ER-465b as shown in Fig. 6. 


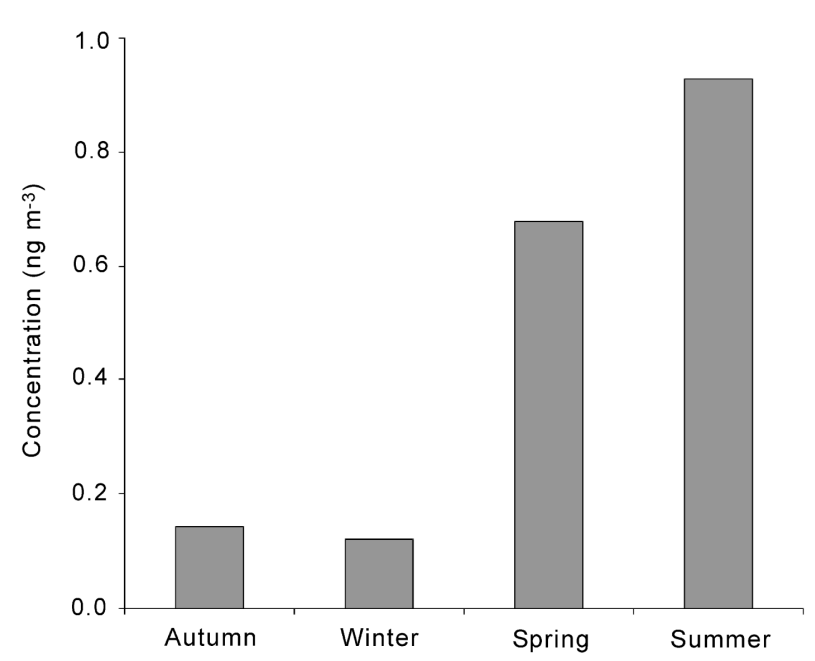

Fig. 8. Ambient concentrations of MBO tracer DHIP measured during a 2006 campaign at Duke Forest in North Carolina.

\subsection{Field measurements}

The gas-phase organic compounds observed in laboratory samples were also present in ambient air. High concentrations of formaldehyde, glyoxal, methylglyoxal, acetaldehyde, acetone, and oxalic acid were observed from MBO oxidation. Data reported in the literature shows that these compounds are ubiquitous in ambient samples and suggests that MBO might be a contributing source of these compounds in areas dominated by trees having high $\mathrm{MBO}$ emission rates. In addition, the uptake of some of these compounds (e.g. glyoxal, methylglyoxal) in the aerosol phase followed by heterogeneous sulfur chemistry can lead to SOA formation (Carlton et al., 2007; Liggio et al., 2005). Recently, Steiner et al. (2007) showed that MBO oxidation causes an increase in ambient ozone, formaldehyde, acetone, and hydroxyl radicals, which can increase the oxidant capacity and chemical reactivity of the atmosphere.

Of greater interest are compounds seen in the present work that might be found in ambient $\mathrm{PM}_{2.5}$. 2-Methylthreitol and 2-methylerythritol were observed previously in ambient $\mathrm{PM}_{2.5}$ and had been thought to have been produced only from the photooxidation of isoprene. From this work, it now appears that the methyltetrols might also have been generated in the atmosphere from the photooxidation of MBO. Additionally, 2,3-dihydroxy-2-methylsuccinic acid observed in this study has been previously reported in ambient $\mathrm{PM}_{2.5}$ samples (Edney et al., 2003) but also appears to be produced during the photooxidation of toluene and 1,3,5-trimethylbenzene. Of the particle-phase compounds that have been detected from the photooxidation of MBO, only DHIP appears unique to this precursor. In fact, in selected ambient samples, particularly those collected in a forested environment, DHIP has been detected and is reported here. Although DHIP was detected in several field samples analyzed by our group (e.g.
CalNex field study, Kleindienst et al., 2011; RTP, midwestern United States, Lewandowski et al., 2008), the field samples analyzed for this paper focus on samples collected from a 2006 field study at Duke Forest in North Carolina. A comparison of a mass spectrum from the laboratory sample with that measured at the field site is shown in Fig. 7. Using the KPA method described above, estimates for ambient concentrations for DHIP were then made and are shown in Fig. 8. The average concentrations of DHIP ranged from $0.1 \mathrm{ng} \mathrm{m}^{-3}$ during the winter season to approximately $1 \mathrm{ng} \mathrm{m}^{-3}$ during the summer season.

Finally, adapting an organic tracer method developed by Kleindienst et al. (2007), a mass fraction of DHIP was measured and used to estimate the SOA contribution from MBO to ambient organic aerosol. For this determination, the collected chamber SOA was analyzed for OC and DHIP, and organic aerosol mass fraction was calculated as described by Kleindienst et al. (2007). An SOA to SOC ratio (SOA/SOC) of 2 was obtained for MBO SOA. Based on experiment ER464 , an average value of the aerosol mass fraction was 0.05 (carbon/carbon). Next, the concentration of the tracer compound was measured in a series of ambient samples from a forested area in North Carolina. 2,3-Dihydroxyisopentanol was detected mainly during the warmest seasons when MBO emissions were high. At $1 \mathrm{ng} \mathrm{m}^{-3}$, the contribution of MBO SOA is estimated to be no more than $0.02 \mu \mathrm{g} \mathrm{m}^{-3}$ of organic mass.

\section{Summary}

Several recent advances have been made in organic aerosol research, and new precursors to SOA are being identified. Although the chemical characteristics of gas-phase reaction products formed from MBO oxidation have been widely studied, relatively few particulate-phase reaction products have been reported, and MBO is generally believed to contribute little to ambient organic aerosol. In the present study, laboratory experiments were carried out to investigate SOA formation from the oxidation of $\mathrm{MBO}$ in the presence and absence of $\mathrm{NO}_{\mathrm{x}}, \mathrm{H}_{2} \mathrm{O}_{2}$, and/or $\mathrm{SO}_{2}$. SOA samples collected under these conditions have been analyzed for organic carbon and organic reaction products using OC/EC analysis and GC-MS, respectively. The resulting analyses show the presence of a large number of oxygenated organic compounds in the gas and filter extracts.

To determine the relative contributions to ambient aerosol of SOA products formed from $\mathrm{MBO}, \mathrm{PM}_{2.5}$ samples were BSTFA derivatized and GC-MS analyzed. Emphasis was placed on polar oxygenated organic compounds. A series of organic compounds were found in both ambient $\mathrm{PM}_{2.5}$ and chamber SOA, but most of these compounds were detected in SOA originating from several hydrocarbon precursors previously studied in our laboratory. 2,3-Dihydroxyisopentanol, however, was detected only in SOA produced from MBO 
oxidation. This compound was further studied to determine its viability to serve as an $\mathrm{MBO}$ organic tracer in atmospheric particulate matter. It was found to be dependent on both the degree of aerosol acidity and MBO levels in ambient $\mathrm{PM}_{2.5}$ samples.

In addition, several aerosol parameters were determined for the first time. OM/OC, for example, is an important parameter for converting SOA into SOC in air quality models and was found in this study to give a value of 2.1. The effective enthalpy of vaporization was $41 \mathrm{~kJ} \mathrm{~mol}^{-1}$, which is similar to that previously measured for isoprene SOA. The SOA yields of up to 0.007 in this work are higher than those reported previously in the literature (Chan et al., 2009). The data presented in this study raise the possibility that MBO could be a measurable contributor to ambient SOA in certain airsheds. Therefore, including MBO into global models becomes crucial, especially in areas where MBO emission rates are known to be high, such as in the western United States.

The results of this study have potential atmospheric implications for areas impacted by MBO oxidation products and should contribute to the understanding of the oxidation of oxygenated precursors. Several compounds were detected and identified in both field and smog chamber experiments. The presence of glyoxal and methyl glyoxal, for instance, and their potential for heterogeneous and multiphase processes is also very interesting. DHIP, which was detected in both field and chamber experiments, is of particular importance because it is specific to MBO. In the absence of authentic standards, however, it is difficult to accurately quantify the contribution of SOA originating from MBO to ambient $\mathrm{PM}_{2.5}$.

Disclaimer: The US Environmental Protection Agency through its Office of Research and Development funded and collaborated in the research described here under Contract EP-D-10-070 to Alion Science and Technology. The manuscript has been subjected to external peer review and has been cleared for publication. Mention of trade names or commercial products does not constitute endorsement or recommendation for use.

Edited by: R. Cohen

\section{References}

Alvarado, A., Tuazon, E. C., Aschmann, S. M., Arey, J., and Atkinson, R.: Products and mechanisms of the gas-phase reactions of $\mathrm{OH}$ radicals and $\mathrm{O}_{3}$ with 2-methyl-3-buten-2-ol, Atmos. Environ., 33, 2893-2905, 1999.

Angove, D. E., Fookes, C. J. R., Hynes, R. G., Walters, C. K., and Azzi, M.: The characterisation of secondary organic aerosol formed during the photodecomposition of 1,3-butadiene in air containing nitric oxide, Atmos. Environ., 40, 4597-4607, 2006.

Atkinson, R.: Atmospheric chemistry of VOCs and $\mathrm{NO}_{\mathrm{x}}$, Atmos. Environ., 34, 2063-2101, 2000.

Baker, B., Guenther, A., Greenberg, J., Goldstein, A., and Fall, R.: Canopy fluxes of 2-methyl-3-buten-2-ol over a ponderosa pine forest by relaxed eddy accumulation: field data and model comparison, J. Geophys. Res., 104, 26107-26114, 1999.

Blunden, J., Aneja, V. P., and Lonneman, W. A.: Characterization of non-methane volatile organic compounds at swine facilities in eastern North Carolina, Atmos. Environ., 39, 6707-6718, 2005.

Carlton, A. G., Turpin, B. J., Altieri, K. E., Seitzinger, S., Reff, A., Lim, H.-J., and Ervens, B.: Atmospheric oxalic acid and SOA production from glyoxal: results of aqueous photooxidation experiments, Atmos. Environ., 41, 7588-7602, 2007.

Carrasco, N., Doussin, J. F., O'Connor, M., Wenger, J. C., PicquetVarrault, B., Durand-Jolibois, R., and Carlier, P.: Simulation chamber studies of the atmospheric oxidation of 2-methyl-3buten-2-ol: reaction with hydroxyl radicals and ozone under a variety of conditions, J. Atmos. Chem., 56, 33-55, 2007.

Chan, A. W. H., Galloway, M. M., Kwan, A. J., Chabra, P. S., Keutsch, F. N., Wennberg, P. O., Flagan, R. C., and Seinfeld, J. H.: Photooxidation of 2-methyl-3-buten-2-ol (MBO) as a potential source of secondary organic aerosol, Environ. Sci. Technol., 43, 4647-4652, 2009.

Charlson, R. J., Schwartz, S. E., Hales, J. M., Cess, R. D., Coakley Jr., J. A., Hansen, J. E., and Hoffman, D. J.: Climate forcing by anthropogenic aerosols, Science, 255, 423-430, doi:10.1126/science.255.5043.423, 1992.

Edney, E. O., Kleindienst, T. E., Conver, T. S., McIver, C. D., Corse, E. W., and Weathers, W. S.: Polar organic oxygenates in $\mathrm{PM}_{2.5}$ at a southeastern site in the United States, Atmos. Environ., 37, 3947-3956, 2003.

Fantechi, G., Jensen, N. R., Hjorth, J., and Peeters, J.: Mechanistic studies of the atmospheric oxidation of methyl butenol by $\mathrm{OH}$ radicals, ozone and $\mathrm{NO}_{3}$ radicals, Atmos. Environ., 32, 3547 3556, 1998.

Geron, C. D. and Arnts, R. R.: Seasonal monoterpene and sesquiterpene emissions from Pinus taeda and Pinus virginiana, Atmos. Environ., 44, 4240-4251, 2010.

Goldan, P. D., Kuster, W. C., Fehsenfeld, F. C., and Montzka, S. A.: The observation of a $\mathrm{C}_{5}$ alcohol emission in a North American pine forest, Geophys. Res. Lett., 20, 1039-1042, 1993.

Gray, D. W.: Transient increases in methylbutenol emission following partial defoliation of Pinus ponderosa, Atmos. Environ., 42, 4797-4802, 2008.

Grosjean, D. and Grosjean, E.: Carbonyl products of the ozoneunsaturated alcohol reaction, J. Geophys. Res., 100, 2281522820, 1995.

Guenther, A., Hewitt, C. N., Erickson, D., Fall, R., Geron, C., Graedel, T., Harley, P., Klinger, L., Lerdau, M., McKay, W. A., Pierce, T., Scholes, B., Steinbrecher, R., Tallamraju, R., Taylor, J., and Zimmerman, P.: A global model of natural volatile organic compound emissions, J. Geophys. Res.-Atmos., 100, 8873-8892, 1995.

Guenther, A., Karl, T., Harley, P., Wiedinmyer, C., Palmer, P. I., and Geron, C.: Estimates of global terrestrial isoprene emissions using MEGAN (Model of Emissions of Gases and Aerosols from Nature), Atmos. Chem. Phys., 6, 3181-3210, doi:10.5194/acp-63181-2006, 2006.

Harley, P., Fridd-Stroud, V., Greenberg, J., Guenther, A., and Vasconcellos, P.: Emission of 2-methyl-3-buten-2-ol by pines: a potentially large natural source of reactive carbon to the atmosphere, J. Geophys. Res., 103, 25479-25486, 1998.

Jaoui, M. and Kamens, R. M.: Mass balance of gaseous and particu- 
late products analysis from alpha-pinene/ $\mathrm{NO}_{\mathrm{x}} /$ air in the presence of natural sunlight, J. Geophys. Res.-Atmos., 106, 12541-12558, 2001.

Jaoui, M., Kleindienst, T. E., Lewandowski, M., and Edney, E. O.: Identification and quantification of aerosol polar oxygenated compounds bearing carboxylic and/or hydroxyl groups. 1. Method development, Anal. Chem., 76, 4765-4778, 2004.

Jaoui, M., Kleindienst, T. E., Lewandowski, M., Offenberg, J. H., and Edney, E. O.: Identification and quantification of aerosol polar oxygenated compounds bearing carboxylic or hydroxyl groups. 2. Organic tracer compounds from monoterpenes, Environ. Sci. Technol., 39, 5661-5673, 2005.

Jaoui, M., Lewandowski, M., Kleindienst, T. E., Docherty, K., and Offenberg, J. H.: Atmospheric oxidation of 1,3-butadiene 1. characterization of gas and aerosol reaction products and implication for $\mathrm{PM}_{2.5}$, in preparation, 2012.

Kanakidou, M., Seinfeld, J. H., Pandis, S. N., Barnes, I., Dentener, F. J., Facchini, M. C., Van Dingenen, R., Ervens, B., Nenes, A., Nielsen, C. J., Swietlicki, E., Putaud, J. P., Balkanski, Y., Fuzzi, S., Horth, J., Moortgat, G. K., Winterhalter, R., Myhre, C. E. L., Tsigaridis, K., Vignati, E., Stephanou, E. G., and Wilson, J.: Organic aerosol and global climate modelling: a review, Atmos. Chem. Phys., 5, 1053-1123, doi:10.5194/acp-5-1053-2005, 2005.

Kim, S., Karl, T., Guenther, A., Tyndall, G., Orlando, J., Harley, P., Rasmussen, R., and Apel, E.: Emissions and ambient distributions of Biogenic Volatile Organic Compounds (BVOC) in a ponderosa pine ecosystem: interpretation of PTR-MS mass spectra, Atmos. Chem. Phys., 10, 1759-1771, doi:10.5194/acp-10-17592010, 2010.

Kleindienst, T. E., Edney, E. O., Lewandowski, M., Offenberg, J. H., and Jaoui, M.: Secondary organic carbon and aerosol yields from the irradiations of isoprene and $\alpha$-pinene in the presence of $\mathrm{NO}_{\mathrm{x}}$ and $\mathrm{SO}_{2}$, Environ. Sci. Technol., 40, 3807-3812, 2006.

Kleindienst, T. E., Jaoui, M., Lewandowski, M., Offenberg, J. H., Lewis, C. W., Bhave, P. V., and Edney, E. O.: Estimates of the contributions of biogenic and anthropogenic hydrocarbons to secondary organic aerosol at a southeastern US location, Atmos. Environ., 41, 8288-8300, 2007.

Kleindienst, T. E., Lewandowski, M., Offenberg, J. H., Jaoui, M., and Edney, E. O.: The formation of secondary organic aerosol from the isoprene $+\mathrm{OH}$ reaction in the absence of $\mathrm{NO}_{\mathrm{x}}$, Atmos. Chem. Phys., 9, 6541-6558, doi:10.5194/acp-9-6541-2009, 2009.

Kleindienst, T. E., Lewandowski, M., Offenberg, J. H., Edney, E. O., Jaoui, M., Zheng, M., Ding, X., and Edgerton, E. S.: Contribution of primary and secondary sources to organic aerosol and $\mathrm{PM}_{2.5}$ at SEARCH network sites, J. Air Waste Manage., 60, 1388-1399, 2010.

Kleindienst, T. E., Offenberg, J. H., Lewandowski, M., Piletic, I., Jaoui, M., Lee, A., Bohnenkamp, C., Hoag, K., Rubitschun, C. L., and Surratt, J. D.: Secondary Organic Aerosol Contributions during CalNex - Bakersfield, CalNex Workshop, Bakersfield, CA, 2011.

König, G., Brunda, M., Puxbaum, H., Hewitt, C. N., Duckham, S. C., and Rudolph, J.: Relative contribution of oxygenated hydrocarbons to the total biogenic VOC emissions of selected midEuropean agricultural and natural plant species, Atmos. Environ., 29, 861-874, 1995.
Kroll, J. H., Ng, N. L., Murphy, S. M., Varutbangkul, V., Flagan, R. C., and Seinfeld, J. H.: Chamber studies of secondary organic aerosol growth by reactive uptake of simple carbonyl compounds, J. Geophys. Res., 110, D23207, doi:10.1029/2005JD006004, 2005.

Lamanna, M. S. and Goldstein, A. H.: In situ measurements of $\mathrm{C}_{2}-\mathrm{C}_{10}$ volatile organic compounds above a Sierra Nevada ponderosa pine plantation, J. Geophys. Res., 104, 21247-21262, 1999.

Lewandowski, M., Jaoui, M., Kleindienst, T. E., Offenberg, J. H., and Edney, E. O.: Composition of $\mathrm{PM}_{2.5}$ during the summer of 2003 in Research Triangle Park, North Carolina, Atmos. Environ., 41, 4073-4083, 2007.

Lewandowski, M., Jaoui, M., Offenberg, J. H., Kleindienst, T. E., Edney, E. O., Sheesley, R. J., and Schauer, J. J.: Primary and secondary contributions to ambient PM in the midwestern United States, Environ. Sci. Technol., 42, 3303-3309, 2008.

Liggio, J., Li, S. M., and McLaren, R.: Reactive uptake of glyoxal by particulate matter, J. Geophys. Res., 110, D10304, doi:10.1029/2004JD005113, 2005.

Noda, J. and Ljungström, E.: Aerosol formation in connection with $\mathrm{NO}_{3}$ oxidation of unsaturated alcohols, Atmos. Environ., 36, 521-525, 2002.

Offenberg, J. H., Kleindienst, T. E., Jaoui, M., Lewandowski, M., and Edney, E. O.: Thermal properties of secondary organic aerosol, Geophys. Res. Lett., 33, 2-5, 2006.

Pope III, C. A., Ezzati, M., and Dockery, D. W.: Fine particulate air pollution and life expectancy in the United States, New Engl. J. Med., 360, 376-386, 2009.

Sisler, J. F. and Malm, W. C.: The relative importance of soluble aerosols to spatial and seasonal trends of impaired visibility in the United States, Atmos. Environ., 28, 851-862, 1994.

Smith, D. F., Kleindienst, T. E., and Hudgens, E. E.: Improved high-performance liquid chromatographic method for artifactfree measurements of aldehydes in the presence of ozone using 2,4-dinitrophenylhydrazine, J. Chromatogr. A, 483, 431-436, 1989.

Spaulding, R. S. and Charles, M. J.: Comparison of methods for extraction, storage and silylation of pentafluorobenzyl derivatives of carbonyl compounds and multi-functional carbonyl compounds, Anal. Bioanal. Chem., 372, 808-816, 2002.

Spaulding, R. S., Schade, G. W., Goldstein, A. H., and Charles, M. J.: Characterization of secondary atmospheric photooxidation products: evidence for biogenic and anthropogenic sources, J. Geophys. Res., 108, 4247, doi:10.1029/2002JD002478, 2003.

Steiner, A. L., Tonse, S., Cohen, R. C., Goldstein, A. H., and Harley, R. A.: Biogenic 2-methyl-3-buten-2-ol increases regional ozone and $\mathrm{HO}_{\mathrm{x}}$ sources, Geophys. Res. Lett., 34, L15806, doi:10.1029/2007GL030802, 2007.

Tarvainen, V., Hakola, H., Hellén, H., Bäck, J., Hari, P., and Kulmala, M.: Temperature and light dependence of the VOC emissions of Scots pine, Atmos. Chem. Phys., 5, 989-998, doi:10.5194/acp-5-989-2005, 2005.

Volkamer, R., San Martini, F., Molina, L. T., Salcedo, D., Jimenez, J. L., and Molina, M. J.: A missing sink for gas-phase glyoxal in Mexico City: formation of secondary organic aerosol, Geophys. Res. Lett., 34, L19807, doi:10.1029/2007GL030752, 2007.

Went, F. W.: Blue hazes in the atmosphere, Nature, 187, 641-643, 1960. 